\title{
Glucose Measurement and Control in Patients with Type 1 or Type 2 Diabetes
}

\author{
Authors \\ Lutz Heinemann', Dorothee Deiss ${ }^{1}, 2$, Thorsten Siegmund ${ }^{1}$, Sandra Schlüter ${ }^{1}$, Michael Naudorf ${ }^{1}$, \\ Simone von Sengbusch ${ }^{2}$, Karin Lange ${ }^{1,2}$, Guido Freckmann ${ }^{1}$
}

\author{
Affiliations \\ 1 Diabetes \& Technology Working Group of the German \\ Diabetes Society e. V., Ulm, Germany \\ 2 Working Group for Pediatric Diabetology e. V., Münster, \\ Germany \\ Bibliography \\ DOI https://doi.org/10.1055/a-1018-9090 \\ Exp Clin Endocrinol Diabetes 2019; 127 (Suppl 1): S8-S26 \\ (C) J. A. Barth Verlag in Georg Thieme Verlag KG \\ Stuttgart · New York \\ ISSN 0947-7349
}

Correspondence

Prof. Dr. Lutz Heinemann

AGDT - Working Group Diabetes \& Technology of the

German Diabetes Society e. V.

Lise-Meitner-Str. 8/2

89081 Ulm

Germany

buero@diabetes-technologie.de

Sandra Schlüter

DSP Northeim

Mühlenstraße 26

37154 Northeim

Germany

sa.schlu@t-online.de

$\begin{array}{ll}\text { ABBREVIATIONS } \\ \text { AGDT } & \text { Working Group for Diabetes \& Technology } \\ \text { AGP } & \text { Ambulatory Glucose Profile } \\ \text { AGPD } & \text { Working Group for Paediatric Diabetology } \\ \text { AID } & \text { Automated Insulin Delivery } \\ \text { CGM } & \text { Continuous Glucose Monitoring } \\ \text { G-BA } & \text { Federal Joint Committee } \\ \text { GOD } & \text { Glucose oxidase } \\ \text { GDH } & \text { glucose hydrogenase } \\ \text { FDA } & \text { Federal Drug Administration } \\ \text { iscCGM } & \text { Intermittent-scanning CGM } \\ \text { ISF } & \text { Interstitial fluid } \\ \text { KV } & \text { Association of Statutory Health Insurance } \\ & \text { Physicians (KV) } \\ \text { MARD } & \text { Mean Absolute Relative Difference rtCGM } \\ & \text { Real-time CGM } \\ \text { SMBG } & \text { Self-measurement of capillary blood glucose } \\ & \text { concentration }\end{array}$

\section{Overview}

Diabetes mellitus is characterized by pronounced glucose fluctuations resulting from missing or insufficient physiological control systems. The aim of diabetes therapy is to limit these fluctuations by administering insulin, antidiabetics or by making lifestyle chang- es. Regular glucose measurements are indispensable for monitoring the progress of diabetes therapy and are used either to make immediate decisions on the appropriate dosage of antidiabetic medication or on the intake of carbohydrates. The retrospective analysis of the metabolic situation using the $\mathrm{HbA} 1 \mathrm{c}$ measurement serves mainly to assess the long-term risk for microvascular and macrovascular complications. The HbA1c value does not, however, provide information about glucose fluctuations that lead to acute complications such as hypoglycaemia and ketoacidosis.

In recent decades, metabolic self-monitoring has been carried out by measuring capillary blood glucose with appropriate monitoring systems (blood glucose meters; SMBG systems). Over the last 30-40 years, these have undergone significant further development in terms of size, manageability and analytical capabilities. Over time, some systems are able to achieve a measurement accuracy that comes close to that of laboratory systems. However, SMBG has the decisive disadvantage of only displaying a single glucose value and cannot make concurrent statements about the change rate and speed (increase, decrease) of glucose. This can result in inappropriate therapy decisions, e. g. by administering corrective insulin when the glucose value is rapidly decreasing. In addition, the amount of SMBG data depends on the patient's ability and decision to perform the measurements. As a result, nightly or asymptomatic hypoglycaemia, for example, often go undetected.

Systems for continuous glucose monitoring (CGM) in interstitial tissue fluid (ISF) have been available for about 15 years: While measurements with SMBG systems under everyday conditions are per- 
formed on average 4-7 times daily in adults with type 1 diabetes, CGM systems provide a complete 24-hour overview and deliver measured values at $5 \mathrm{~min}$ intervals. The registered CGM profiles visualize the glucose trend, i. e. they display fluctuations in glucose concentrations which are the result of metabolic processes which are both relatively unpredictable and only partly influenceable, such as meals, physical activities, stress, illness, etc. In order to improve glucose control, timely knowledge of the current glucose value and its dynamics is important information in order to both optimize it and avoid acute complications. Although satisfactory glucose control is possible in many patients who perform sufficiently frequent SMBG measurements, CGM can promote participation in life and reduce psychological stress. This applies in particular to children with type 1 diabetes who are not yet able to identify physical symptoms, e. g. hypoglycaemia. The number of blood glucose measurements required daily is often more than 20 - which often places a high burden on both children and parents. This is especially the case for regular night-time measurements. Furthermore, CGM systems are a technical innovation that enable systems with Automated Insulin Delivery (AID).

In the past, it was difficult for people with diabetes to practice professions in which they could have endangered themselves and other people in the event of a hypoglycaemia, e. g. pilot, bus driver or policeman. Thanks to CGM systems, these people can participate in working life and are able to learn their living (provided for by law in $\S 49$ SGB (German Social Code/Sozialgesetzbuch) IX and necessary and sensible for society as a whole).

In practice, systems called the real-time CGM systems (rtCGM) are used which directly display the measurement results. Current glucose values are displayed numerically and graphically, as are glucose trends which indicate the direction and change rate of the glucose value. Programmable alarms that warn of hypoglycaemia and hyperglycaemia provide additional safety. However, long-term metabolic optimisation requires continuous use of the rtCGM systems and how patients use CGM systems in real life has not yet been examined in depth.

The current generations of rtCGM systems have considerably improved measurement accuracy compared to systems of earlier generations. Irrespective of this, there may be deviations between the measured concentrations in the two compartments of blood and tissue glucose due to a physiological time lag, especially in the case of rapid increases and decreases in the glucose trend. The rtCGM systems are usually based on what are called needle sensors, which enable the measured glucose values to be displayed directly on special receiving and display devices (handhelds), insulin pumps or via an app on a smartphone. As an alternative to the needle sensors which must be replaced every seven to ten days, an implantable long-term sensor for an rtCGM system (service life up to 6 months) is currently available.

Another frequently used variant of CGM systems is a needle sensor system called intermittent scanning CGM (iscCGM) in which the reader must be held close to the sensor to scan the measured values. After scanning, the current glucose value and the retrospective continuous glucose data (determined every $15 \mathrm{~min}$ ) of the last $8 \mathrm{~h}$ are displayed. This system cannot be calibrated. This CGM system is also used by patients with type 2 diabetes and is an alternative to SMBG. Another advantage of this system is the lower costs.
IscCGM can also be an important training tool where it is only used for a short period of time, depending on the situation. Being able to evaluate all the factors which influence the glucose course is very informative. One disadvantage of the first-generation systems was the lack of alarms. Nonetheless, thanks to the relatively simple and fast scanning, it was already possible to reduce the number of hypoglycaemia and hyperglycaemia with that first generation of devices. The second generation of devices now offers alarm functions (see below).

Current evaluations from the USA of a large number of patients with type 1 diabetes who use CGM systems point to a lack of improvement in glucose control among many users. In our view, this is evidence that simply providing technical options is not sufficient per se, but that patients and diabetes teams must be fully trained in the proper use of this diagnostic option. In addition, regular retrospective data analysis is necessary to adapt the therapy to achieve sustained metabolic improvement. Many patients only make therapy adjustments using the real-time display of their display device or smartphone to react to the displayed current glucose value and the trend arrow ("navigation aid"). They do not download the CGM data to a computer or smartphone at regular intervals in order to assess the overall progress over time. For this reason, this should always be done during doctor-patient consultations, even if this exchange can be time-consuming. The manufacturers support users with ever better software solutions for evaluating CGM data. Such analyses can also provide concrete indications for the modification of diabetes therapy. All in all, the patient should have an active view of the glucose levels and work with them. The physician and the diabetic test team should also regularly support the patient with a constructive data analysis.

In the following, the various options for glucose measurement using a uniform structure are explained. The decision tree in ( provides a quick overview of which glucose measurement system is best suited for which individual patient. The starting point is the patient coming to the practice or clinic. The diabetes team then needs to recognize the patient's medical needs and discuss the various options for glucose measurement. The patient, diabetologist and diabetes consultant should all jointly make the decision as to which option is best for the patient. The CGM system used should be changed if it does not properly meet the medical needs of the patient. A product change might, however, require a certain amount of lead time due to the validity duration of a prescription.

The decision as to which system fits the patient best should be guided primarily by medical and social indications (e. g. hypoglycaemia, pregnancy, professional life and private life), not by economic aspects. SMBG is the first level that every patient should master and use. Only then should a conversion to rtCGM/iscCGM take place. The decision as to which of the two CGM options currently offered is suitable depends on the individual conditions of the patient. Intensive training in the selected form of diabetes therapy is a prerequisite and is essential when choosing CGM. If the possibilities of rtCGM are not being used fully, switching to iscCGM is an option. Conversely, if the therapy goals are not being achieved or if glucose control is unstable under iscCGM, it may be useful to switch to rtCGM. Not adhering to rtCGM or iscCGM should lead to ending the use of these systems. 


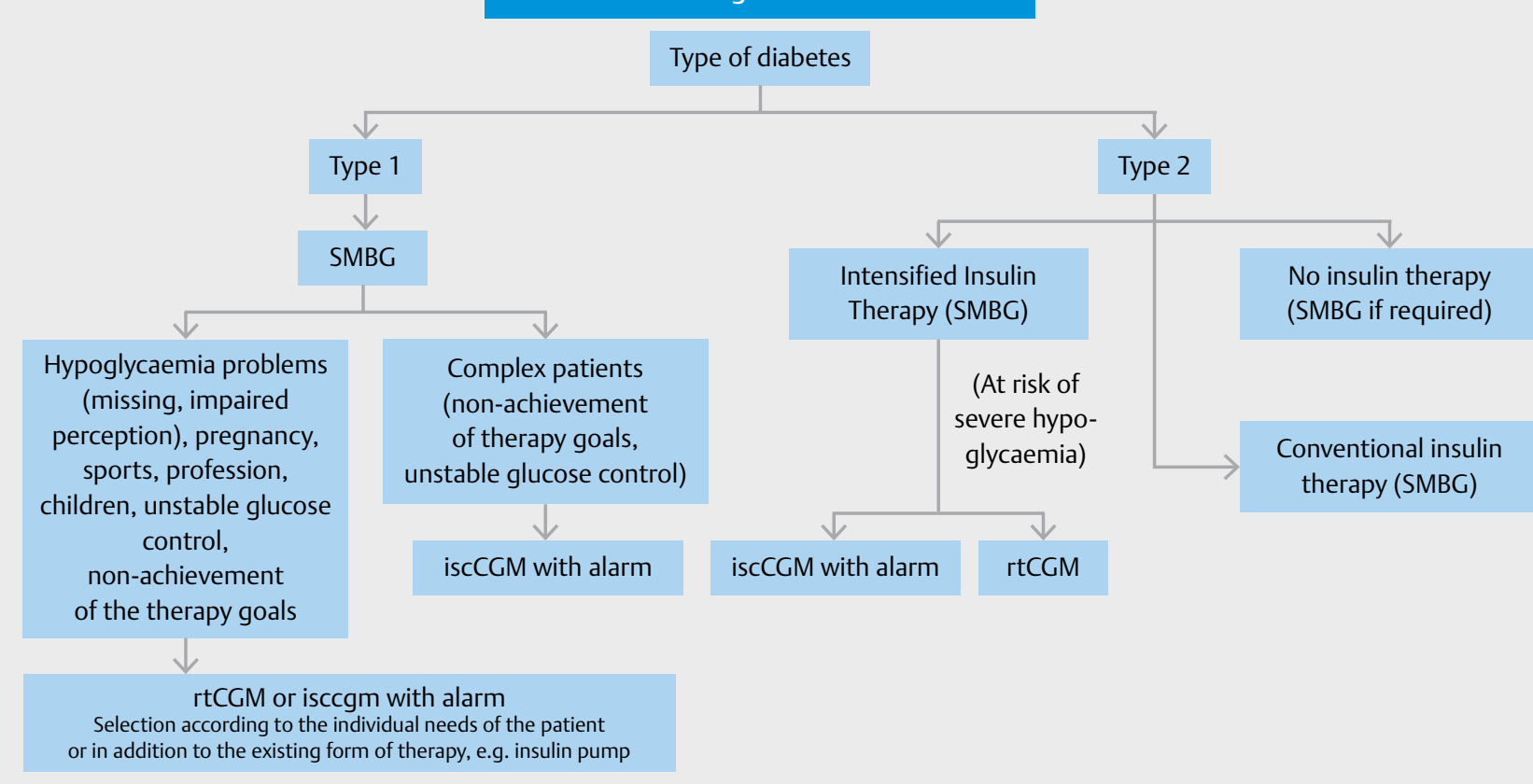

- Fig. 1 Decision tree for the various glucose measurement options. SMBG = self-measurement of capillary blood glucose concentration; $\mathrm{CGM}=$ continuous glucose monitoring; rtCGM = real-time CGM, iscCGM = intermittent-scanning CGM.

The procedure may differ for children. Nowadays they often first receive an insulin pump and a CGM system quickly follows. In many cases, children under 2 years of age receive both directly because up to 20 SMBG measurements per day are too stressful for both child and parents. This patient group benefits greatly from the new technical options.

Statements on the therapeutic use of the glucose monitoring values obtained by various patient groups are made in the respective DDG (German Diabetes Society/Deutsche Diabetes Gesellschaft) practical recommendations.

These practical recommendations do not mention product names for blood glucose monitoring systems, although there is a clear need for a positive list. Similarly, no information is provided on the technical details of specific products, as their further development is too rapid (see the manufacturers' homepages).

This practical recommendation is not an evidence based S3 guideline and, accordingly, statements are not supported by literature quotations. The recommendations are based on the clinical and practical experience of the authors and the evidence derived from studies for the purpose of the achieving the best possible usability in everyday life. As well, no statements are made on the diabetes diagnosis and the use of glucose measurement systems to do so (see the corresponding practical recommendation).

The authors of this practical recommendation are members of Working Group for Diabetes and Technology/AG Diabetes \& Technologie e. V. (AGDT) and/or the Working Group for Paediatric Diabetology/Arbeitsgemeinschaft für Pädiatrische Diabetologie e. V., (AGPD), which are working groups under the umbrella of the DDG.
The AGDT has issued a number of statements and publications on aspects which are dealt with in this practical recommendation; these can be found on the DDG and AGDT homepages. This practical recommendation was created together with the Commission for Laboratory Diagnostics in Diabetology/ Kommission für Labordiagnostik in der Diabetologie (KLD). Statements also come from the current $\mathrm{S} 3$ guideline on type 1 diabetes, published in March 2018, and the S3 guideline for children and adolescents [Neu A, Bürger- Büsing J, Danne T, Dost A, Holder M, Holl RW, Holterhus PM, Kapellen T, Karges G, Kordonouri O, Lange K, Müller S, Raile K, Schweizer R, von Sengbusch S, Stachow R, Wagner V, Wiegand S, Ziegler R. Diagnosis, Therapy and Follow-Up of Diabetes Mellitus in Children and Adolescents/ Diagnostik, Therapie und Verlaufskontrolle des Diabetes mellitus im Kindes- und Jugendalter. S3 guideline of the DDG and AGPD 2015, AWMF registration number 057016 @ Deutsche Diabetes Gesellschaft (DDG) 2015. p. 1-18], which was published under the leadership of the AGPD in 2015.

\section{Self-Measurement of Capillary Blood Glucose Concentration (SMBG)}

\section{Goals/Indications}

In order to achieve the therapy goals (e. g. an HbA1c value set with the treating physician, reduction of hypoglycaemia, improvement of the preprandial or postprandial BG values), properly trained patients with diabetes mellitus regularly measure the glucose concentration in capillary blood samples to monitor the glucose trend 
(information on the correctly performing the measurement is found in ( $\triangleright$ Table 1). Blood glucose measurements are also used to detect acute metabolic disorders (hypoglycaemia or hyperglycaemia).

With different therapy approaches (oral therapy, bedtime insulin administration, conventional insulin therapy (CT), intensified insulin therapy (ICT), insulin pump therapy (CSII)) and different diabetes types (type 1, type 2 with and without insulin therapy, pancreatic diabetes mellitus, gestational diabetes and others), different times and frequencies for measuring blood glucose concentrations are common and objectively indicated ( $>$ Table 2 ). The glucose measurement results are used to adjust the insulin dose or other antidiabetic drugs, modify exercise to the current glucose situation or carbohydrate intake for an (imminent) hypoglycaemia.

There is a clear indication for SMBG in patients with type 1 or insulin-dependent type 2 diabetes.

Measuring glucose not only involves proper patient training on how to precisely and correctly perform the glucose measurements, but it also necessary to have an understanding of how the measurement results are converted into therapeutic steps.

\section{Frequency of measurements}

Patients with type 1 diabetes and ICT with multiple insulin injections daily or an insulin pump should measure blood glucose concentration at least 4 times daily (preprandial and before bedtime) and every 2-3 weeks during the night. In addition, measurements may be taken in special situations, e. $g$. to check the effects of meals, in suspected hypoglycaemia, sport, illness, holidays, when driving a car, etc. This results in an average need for at least 5 glucose test strips per day ( $\triangleright$ Table 2 ). Patients with type 1 diabetes and hypoglycaemia perception disorder form a special group. In addition to the measurement times already described, measurements are carried out before each car journey, during physical activity, during sport and during everyday work. This results in a quarterly requirement of at least 800 test strips. The need for test strips in children, especially toddlers, increases even further as children cannot reliably express themselves regarding the symptoms of hypoglycaemia or hyperglycaemia and are also more prone to much faster and more intense glucose fluctuations than adults with type 1 diabetes.

Patients with insulin-dependent type 2 diabetes with ICT should also determine preprandial and occasionally postprandial glucose

> Table 1 Practical procedure in capillary blood glucose measurement.

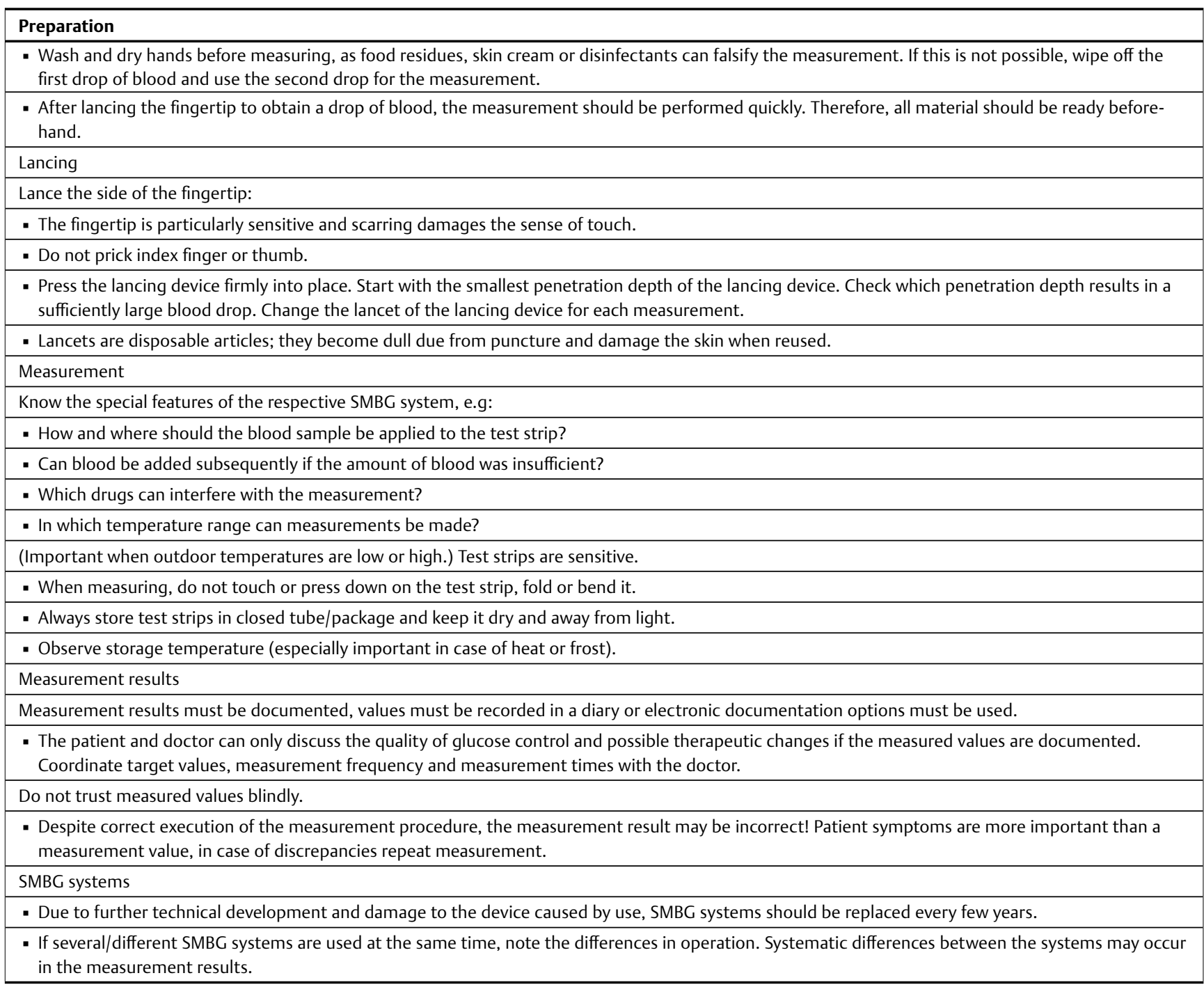


- Table 2 Recommendations for the use of SMBG in the various types of diabetes and forms of therapy.

\begin{tabular}{|c|c|c|c|c|c|}
\hline Diabetes & Therapy & $\begin{array}{l}\text { Measurement } \\
\text { frequency }\end{array}$ & $\begin{array}{l}\text { Measurement situation } \\
\text { Preprandial: before the meal } \\
\text { Postprandial: } 1.5 \mathrm{~h} \text { after meal }\end{array}$ & $\begin{array}{l}\text { Measurement } \\
\text { interval }\end{array}$ & Test strip requirement \\
\hline \multirow[t]{3}{*}{ Type 1} & \multirow[t]{3}{*}{ ICT } & \multirow[t]{3}{*}{ At least $5 \times$ daily } & $\begin{array}{l}\text { Preprandial and possibly postprandial, } \\
\text { before going to bed }\end{array}$ & On a daily basis & \multirow{3}{*}{$\begin{array}{l}>5 \text { strips daily } \\
\text { At least } 600 \text { strips per } \\
\text { quarter }\end{array}$} \\
\hline & & & At night (2:00 a.m. to 4:00 a.m.) & Every 2-3 weeks & \\
\hline & & & $\begin{array}{l}\text { In special situations (suspected hypoglycae- } \\
\text { mia, sport, illness, before driving ...) }\end{array}$ & When required & \\
\hline \multirow[t]{3}{*}{$\begin{array}{l}\text { Type } 1 \text { children and } \\
\text { adolescents }\end{array}$} & \multirow[t]{3}{*}{ ICT } & \multirow[t]{3}{*}{$\begin{array}{l}\text { At least } \\
10 \times \text { daily }\end{array}$} & $\begin{array}{l}\text { Preprandial, postprandial, before going to } \\
\text { bed, at night }\end{array}$ & On a daily basis & \multirow{3}{*}{$\begin{array}{l}>10 \text { strips daily } \\
\text { At least } 1000 \text { strips per } \\
\text { quarter }\end{array}$} \\
\hline & & & In special situations (before/at/after sports, & When required & \\
\hline & & & During feverish infectious diseases ...) & Every $2-3 \mathrm{~h}$ & \\
\hline \multirow[t]{3}{*}{ Type 1} & \multirow{3}{*}{$\begin{array}{l}\text { Insulin } \\
\text { pump }\end{array}$} & \multirow[t]{3}{*}{ At least $5 \times$ daily } & Preprandial and possibly postprandial, & On a daily basis & \multirow{3}{*}{$\begin{array}{l}>5 \text { strips daily } \\
\text { At least } 600 \text { strips per } \\
\text { quarter }\end{array}$} \\
\hline & & & $\begin{array}{l}\text { Before going to bed at night (2:00 a.m. to } \\
\text { 4:00 a.m.) }\end{array}$ & Every 2-3 weeks & \\
\hline & & & $\begin{array}{l}\text { In special situations (suspected hypoglycae- } \\
\text { mia, sport, illness, before driving, technical } \\
\text { mistake ...) }\end{array}$ & When required & \\
\hline \multirow[t]{3}{*}{$\begin{array}{l}\text { Type } 1 \text { children and } \\
\text { adolescents }\end{array}$} & \multirow[t]{3}{*}{$\begin{array}{l}\text { Insulin } \\
\text { pump }\end{array}$} & \multirow[t]{3}{*}{$\begin{array}{l}\text { At least } \\
12 \times \text { daily }\end{array}$} & $\begin{array}{l}\text { Preprandial, postprandial, before going to } \\
\text { bed, at night }\end{array}$ & On a daily basis & \multirow{3}{*}{$\begin{array}{l}>12 \text { strips daily } \\
\text { At least } 1200 \text { strips per } \\
\text { quarter }\end{array}$} \\
\hline & & & $\begin{array}{l}\text { In special situations (before, during or after } \\
\text { sports), }\end{array}$ & When required & \\
\hline & & & $\begin{array}{l}\text { During infectious diseases, technical } \\
\text { mistake ...) }\end{array}$ & Every $2-3 \mathrm{~h}$ & \\
\hline \multirow{3}{*}{$\begin{array}{l}\text { Type } 1 \text { with } \\
\text { hypoglycaemia } \\
\text { perception disorder }\end{array}$} & \multirow[t]{3}{*}{$\begin{array}{l}\text { ICT/insulin } \\
\text { pump }\end{array}$} & \multirow[t]{3}{*}{ At least $8 \times$ daily } & $\begin{array}{l}\text { Preprandial and postprandial, before going } \\
\text { to bed }\end{array}$ & On a daily basis & \multirow{3}{*}{$\begin{array}{l}>8 \text { strips daily } \\
\text { At least } 800 \text { strips per } \\
\text { quarter }\end{array}$} \\
\hline & & & At night (2:00 a.m. to 4:00 a.m.) & Every 2 weeks & \\
\hline & & & $\begin{array}{l}\text { In special situations (suspected hypoglycae- } \\
\text { mia, sport, illness, before driving, technical } \\
\text { mistake ...) }\end{array}$ & When required & \\
\hline \multirow[t]{3}{*}{ Type 2} & \multirow[t]{3}{*}{ ICT } & \multirow[t]{3}{*}{ At least $4 \times$ daily } & $\begin{array}{l}\text { Preprandial and possibly postprandial, } \\
\text { before going to bed }\end{array}$ & On a daily basis & \multirow{3}{*}{$\begin{array}{l}>4 \text { strips daily } \\
\text { At least } 500 \text { strips per } \\
\text { quarter }\end{array}$} \\
\hline & & & At night (2:00 a.m. to 4:00 a.m.) & Every 2-3 weeks & \\
\hline & & & $\begin{array}{l}\text { In special situations (suspected hypoglycae- } \\
\text { mia, sport, illness, before driving ...) }\end{array}$ & When required & \\
\hline \multirow[t]{3}{*}{ Type 2} & \multirow[t]{3}{*}{ CT } & \multirow[t]{3}{*}{ At least $2 \times$ daily } & Preprandial (before injection) & Daily & \multirow{3}{*}{$\begin{array}{l}>2 \text { strips daily } \\
\text { At least } 250 \text { strips per } \\
\text { quarter }\end{array}$} \\
\hline & & & At night (2:00 a.m. to 4:00 a.m.) & Every 2-3 weeks & \\
\hline & & & $\begin{array}{l}\text { In special situations (suspected hypoglycae- } \\
\text { mia, sport, illness, before driving ...) }\end{array}$ & When required & \\
\hline \multirow[t]{3}{*}{ Type 2} & \multirow{3}{*}{$\begin{array}{l}\text { Bedtime } \\
\text { insulin }\end{array}$} & At least $2 \times$ daily & Preprandial fasting, before going to bed & On a daily basis & >2 strips daily \\
\hline & & & At night (2:00 a.m. to 4:00 a.m.) & Every $2-3$ weeks & At least 200 strips per \\
\hline & & & $\begin{array}{l}\text { In special situations (suspected hypoglycae- } \\
\text { mia, sport, illness, before driving ...) }\end{array}$ & When required & \\
\hline Type 2 with & Sulfonylurea & At least $2 \times$ per & Preprandial fasting, before going to bed & $1 \times$ per week & $>1 / 2$ strip daily \\
\hline hypoglycaemıa risk & therapy & week & At night (2:00 a.m. to 4:00 a.m.) & Every 2-3 weeks & At least 50 strips per \\
\hline & & & $\begin{array}{l}\text { In special situations (suspected hypoglycae- } \\
\text { mia, sport, illness, before driving ...) }\end{array}$ & When required & \\
\hline $\begin{array}{l}\text { Type } 2 \text { without } \\
\text { hypoglycaemic risk }\end{array}$ & Oral therapy & & $\begin{array}{l}\text { In special situations (manifestation, for } \\
\text { training purposes, failure to achieve the } \\
\text { therapy goals ...) }\end{array}$ & When required & $\begin{array}{l}\text { At least } 50 \text { strips per } \\
\text { quarter }\end{array}$ \\
\hline $\begin{array}{l}\text { Type 1/Type } 2 \\
\text { Pregnancy }\end{array}$ & $\begin{array}{l}\text { ICT/insulin } \\
\text { pump }\end{array}$ & At least $7 \times$ daily & $\begin{array}{l}\text { Preprandial and postprandial, before going } \\
\text { to bed }\end{array}$ & On a daily basis & $\begin{array}{l}>7 \text { strips daily } \\
\text { At least } 700 \text { strips per }\end{array}$ \\
\hline & & & At night (2:00 a.m. to 4:00 a.m.) & On a weekly basis & quarter \\
\hline & & & $\begin{array}{l}\text { In special situations (suspected hypoglycae- } \\
\text { mia, sport, illness, before driving, technical } \\
\text { mistake ...) }\end{array}$ & When required & \\
\hline
\end{tabular}


> Table 2 Continued

\begin{tabular}{|c|c|c|c|c|c|}
\hline Diabetes & Therapy & $\begin{array}{l}\text { Measurement } \\
\text { frequency }\end{array}$ & $\begin{array}{l}\text { Measurement situation } \\
\text { Preprandial: before the meal } \\
\text { Postprandial: } 1.5 \mathrm{~h} \text { after meal }\end{array}$ & $\begin{array}{l}\text { Measurement } \\
\text { interval }\end{array}$ & Test strip requirement \\
\hline \multirow[t]{2}{*}{ Gestational diabetes } & \multirow[t]{2}{*}{ Nutrition } & \multirow{2}{*}{$\begin{array}{l}\text { At least } 15 \times \text { per } \\
\text { week }\end{array}$} & Fasting, & On a daily basis & \multirow{2}{*}{$\begin{array}{l}\text { At least } 350 \text { strips per } \\
\text { quarter }\end{array}$} \\
\hline & & & $\begin{array}{l}\text { Preprandial and postprandial, before going } \\
\text { to bed }\end{array}$ & $3 \times$ per week & \\
\hline \multirow[t]{3}{*}{ Gestational diabetes } & \multirow[t]{3}{*}{ Insulin } & \multirow[t]{3}{*}{ At least $7 \times$ daily } & $\begin{array}{l}\text { Preprandial and postprandial, before going } \\
\text { to bed }\end{array}$ & On a daily basis & \multirow{3}{*}{$\begin{array}{l}>7 \text { strips daily } \\
\text { At least } 650 \text { strips per } \\
\text { quarter }\end{array}$} \\
\hline & & & At night (2:00 a.m. to 4:00 a.m.) & Every 2 weeks & \\
\hline & & & $\begin{array}{l}\text { In special situations (suspected hypoglycae- } \\
\text { mia, sport, illness, before driving, technical } \\
\text { mistake ...) }\end{array}$ & When required & \\
\hline
\end{tabular}

levels and measure them before bedtime. The daily requirement is at least $4-5$ test strips, which corresponds to at least 500 test strips per quarter. Patients with insulin-dependent type 2 diabetes and CT or bedtime therapy require at least 1-2 measurements per day; the quarterly requirement is therefore at least 150-250 test strips.

Patients with non-insulin-dependent type 2 diabetes undergoing sulfonylurea therapy require test strips for detecting hypoglycaemia.

Practical experience shows a requirement of at least 50 test strips per quarter.

It makes medical sense to provide all patients with type 2 diabetes and oral antidiabetic therapy with at least 50 test strips per quarter in case of manifestation or for training purposes or if the therapy goals are not achieved.

Pregnant women with a pre-existing type 1 or type 2 diabetes perform preprandial and postprandial glucose measurements, resulting in a requirement of at least 7 test strips per day, i. e. at least 700 test strips per quarter. Women with gestational diabetes should always measure fasting blood glucose and postprandial glucose 2-3 times per week. In cases of insulin dependence, regular preprandial and postprandial glucose measurements are necessary which leads to a requirement of at least 7 test strips per day.

\section{Measurement method}

In the SMBG systems commonly used by patients, the enzyme used is either glucose oxidase (GOD) or glucose hydrogenase (GDH). The glucose oxidase method is susceptible to substance and drug interferences (e.g. ascorbic acid, paracetamol, blood oxygen content). As well, relevant interferences must be taken into account, especially in patients with multimorbidities (interferences caused by medications, uric acid, etc.). For patients with high or low haematocrit values, the monitoring systems (manual/test strip package insert) should be checked for compatibility to the patient.

\section{Available systems}

There are many different SMBG systems currently available from various suppliers. Overviews of the properties of these systems are primarily based on the information provided by the manufacturers. Many modern SMBG systems have additional functions, such as data storage and readout, marking of values as preprandial or postprandial, colour coding of displayed values for immediate assessment, a light at the test strip slot, bolus calculators, calculation of an estimated $\mathrm{HbA} 1 \mathrm{c}$ value or the possibility of transmitting data to an app/cloud (connectivity).

\section{Specifications for measurement quality/standards}

Like all medical devices, blood glucose monitoring systems have CE marking. CE marking is not a mark of quality and after the introduction of the systems to the market, there is no systematic evaluation of their measurement quality. Over time, many independent evaluations have shown that some systems on the market exhibit inadequate measurement quality.

The SMBG systems currently available on the market must meet the requirements of ISO Standard 15 197:2015.

\section{Costs/Refund of expenses}

Health insurance covers the costs for blood glucose monitoring systems (device and test strips) for patients with type 1 diabetes and patients with insulin-dependent type 2 diabetes.

Patients with type 2 diabetes who do not undergo drug therapy or who take oral antidiabetics without a hypoglycaemic risk are only covered by statutory health insurance in special situations (unstable metabolic conditions, readjustment or change with an increased risk of hypoglycaemia).

The prescribing physician shall determine the number of test strips deemed appropriate for the given insulin-dependent patient. An exact indication is important. For example, a manifestation or pregnancy with type 1 or type 2 diabetes has a significantly higher test strip consumption ranking than in CT does. In reality, the prescribability of blood glucose test strips is regulated by a Federal Joint Committee/Gemeinsamer Bundesausschuss (G-BA) decision and is laid down in the Pharmaceutical Directives/Arzneimittel Richtlinien Annex III (Overview of prescription restrictions and exclusions/ Übersicht über Verordnungseinschränkungen und -ausschlüsse). The Association of Statutory Health Insurance Physicians/ Kassenärztliche Vereinigungen (KV) regulates the prescription of blood glucose meters and test strips. The health insurance companies and the KV signed a common guiding framework, agreements and contracts leading to joint recommendations as to which costs are covered for which type of diabetes and of therapy. These recommendations are, however, not binding.

\section{Quality control (Internal and external/ Interlaboratory comparisons)}

Quality control for personal glucose measurement systems can be performed with a system-specific control solution. Ideally, quality control should be carried out at home every time a new test strip 
package is opened and for the situations specified in the operating instructions.

According to the German Medical Association guidelines (Rili$B \ddot{K}$ ), SMBG systems used for glucose measurement in laboratories, clinics and practices must meet the requirements for internal quality control (control solution measurements) but not those for external quality control (interlaboratory comparisons). The internal quality control for SMBG systems in use must be carried out regularly in every practice. The implementation of external quality control by participating in interlaboratory comparisons can provide additional information on measurement quality.

\section{Safety issues/Side effects}

An incorrect SMBG measurement results in the administration of an incorrect insulin dose, which can have immediate and significant consequences such as severe hypoglycaemia. Therefore, when training patients, it is imperative to focus on the prerequisites for correct glucose measurement using SMBG systems ( $>$ Fig. 2).

For the patient, lancing a fingertip to obtaining a blood drop can be a painful procedure. Despite the modern lancing devices available today, lancing is still felt and repeatedly lancing the same sites can lead to considerable scarring of the fingertips and reduced sensitivity in the future.

Younger children, who do not yet understand the necessity of these measures, may experience considerable psychological stress and disturbance of the parent-child relationship. Nonetheless, even for adult patients, the pain that is self-inflicted several times a day can be a psychological burden.

\section{Practical implementation of the measurement}

During the measurement, it is important to consider the factors that are important for a correct measurement ( $\triangleright$ Fig. 2) (see Guidelines for Blood Glucose Self-Monitoring/Leitfaden zur Blutzuckerselbstkontrolle: https://www.vdbd.de/Downloads/BlutzuckerSelbstkontrolle-Stand1142 014.pdf.

\section{Use with different patient groups}

The market is usually only divided into patients with type 1 or type 2 diabetes and women with gestational diabetes. In reality, however, there are a number of subgroups, especially when it comes to SMBG. There are hardly any monitoring systems on the market that are suitable for patients with impaired vision or for the blind (devices with speech output or acoustic instructions for use). The same applies to elderly patients with limited manual dexterity. They need devices with simple operation and a clearly legible display.

\section{Training/Psychological aspects}

The preparatory steps for SMBG, in particular obtaining a capillary blood drop, as well as correctly performing the actual measurement require theoretical and practical training. Ideally, this should be done using the system that the patient will later use. A one-off introduction is often not enough, i. e. the various steps to be taken should be repeatedly trained, discussed and closely supervised.

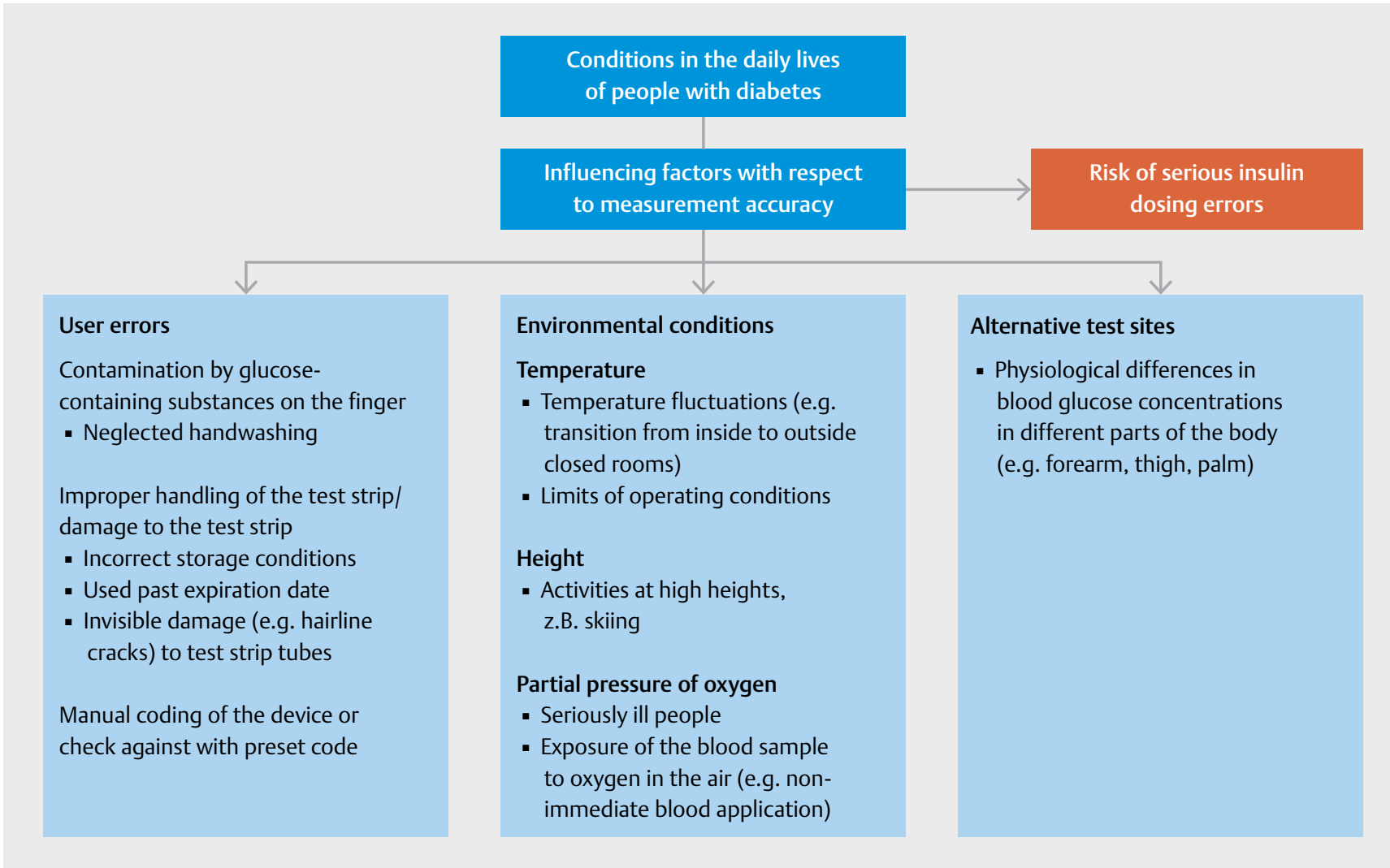

Fig. 2 Factors which influence the SMBG measurement result. 
Since performing SMBG in public (school, workplace, restaurant, etc.) makes it visible that the person is suffering from diabetes, those affected often do not perform a measurement in such situations. This can entail significant risks as acute glucose derailments are then not detected. The patients' understandable desire for discretion makes other glucose monitoring options (see below) attractive. However, not all patients want to permanently wear a technical device on their body or be disturbed by alarms.

\section{Comment}

The performance of SMBG monitoring systems has improved in recent decades to such an extent that considerable further improvements are no longer to be expected in the foreseeable future. SMBG systems still have the largest market share of glucose monitoring systems in the field of diabetes technology - in part, due to the lower costs compared to rtCGM/iscCGM systems. Continuous measurement systems such as rtCGM and iscCGM, however, are gaining in acceptance and importance.

One important option for further development of SMBG systems is their interoperability, i. e. improved automatic availability of measurement results for evaluating data in programs or apps. In the future, the merging of data including those from the insulin dose (by using smart pens), carbohydrates (by an automated analysis of the carbohydrate content of meals) or exercise (by using data from fitness wristbands) will enable the calculation of the optimal insulin dose thanks to the possibility of analysing data from many sources. Future bolus calculators will be able to process such data and thus relieve patients of error-prone calculations.

\section{Real-time CGM (rtCGM)}

\section{Goals/Indications}

When using rtCGM systems, therapy goals can be better achieved by increasing the quality and quantity of information (continuous display of the current glucose value, trend display and alarms when pre-set limit values are reached) ( $\triangleright$ Tables 3,4$)$. The continuous use of rtCGM systems can enable motivated users to achieve their therapy goals of reducing: the HbA1c value, glucose variability, hypoglycaemic frequency and duration and the occurrence of severe hypoglycaemia. The indication of the current glucose value, the current trend as well as the glucose trend over the last 3/6/12/24 h helps both in assessing the current glucose control and in assessing the effect of therapeutic interventions on food intake, physical activity or other influencing factors. Patients must make proper use of the quantity and quality of information offered and translate it into therapeutic interventions. To master such a complex task, patients must be trained in theory and practice and become technically proficient at using their rtCGM system.

Indications for using rtCGM apply for the following patient groups (> Fig. 1):

- Type 1 diabetes

- Type 2 diabetes with ICT

- Table 3 Factors that have an influence on the CGM measurement result.

Application error:

- Calibration with CGM values instead of blood sugar values

- Calibration during rapid increase, rapid fall or hypoglycaemia

- No calibration, although it would be appropriate and possible

- Calibration with contaminated fingers

- Positioning of the sensor in individually unfavourable areas (too little, too much fatty tissue)

Environmental conditions:

- Sensor insertion site (upper arm, abdomen, thigh, buttocks) with individually variable blood circulation

- Pressure on the sensor position by belt, waistband, sleeping position (false low values, poor reception at the end device)

- Inflammations of the skin at the insertion site of the sensor

- A several millimetre-high skin patch, which places a part of the sensor in the fatty tissue and a part in the patch.

- Paracetamol as interfering substance for some sensors (false high values)

> Table 4 Parameters for characterizing CGM data (retrospective analysis).

\begin{tabular}{|c|c|c|}
\hline \multicolumn{3}{|c|}{ Consensus ATTD: all parameters should be available to assess CGM data } \\
\hline \multicolumn{2}{|l|}{ Time-in-Range/Time-in-target-Range (TIR): > 70} & $70-180 \mathrm{mg} / \mathrm{dl} 3.8-10 \mathrm{mmol} / \mathrm{I}$ \\
\hline \multirow[t]{3}{*}{ Hypoglycaemia <4\% } & Level 1 & $70 \mathrm{mg} / 13.9 \mathrm{mmol} / \mathrm{l}$ \\
\hline & Level 2 & $54 \mathrm{mg} / \mathrm{dl} 3.9 \mathrm{mmol} / \mathrm{l}$ \\
\hline & Severe hypoglycaemia & External help required \\
\hline \multirow[t]{3}{*}{ Hyperglycaemia } & Level 1 & $>180 \mathrm{mg} / \mathrm{dl}>10 \mathrm{mmol} / \mathrm{l}$ \\
\hline & Level 2 & $>250 \mathrm{mg} / \mathrm{dl}>13.8 \mathrm{mmol} / \mathrm{l}$ \\
\hline & Ketoacidosis & Clinical diagnosis \\
\hline Glycaemic variability & & Coefficient of variation/standard deviation \\
\hline Mean glucose value & & - \\
\hline Estimated HbA1c & & - \\
\hline CGM visualization & & Ambulatory glucose profile (AGP) \\
\hline Episodes of hyper-, hypoglycaemia & & At least 15 min duration \\
\hline Night and day times & & 00:00 a.m. to 6:00 a.m.; 6:00 a.m. until 11:59 PM \\
\hline $\begin{array}{l}\text { Recommendation on the amount of data that should be } \\
\text { available for evaluation }\end{array}$ & & At least 2 weeks with $70 \%-80 \%$ CGM data \\
\hline
\end{tabular}


- Insulin-dependent diabetes with frequent hypoglycaemia or

- hypoglycaemia disorder

- Pregnancy with pre-existing insulin-dependent diabetes

In consultation between patient and physician, an individual decision must be made as to whether rtCGM use is medically necessary and sensible ( Figs. 1, 3). The significant benefit of rtCGM for many patients is indisputable, although it might not be indicated for every patient. A test phase can be helpful for the patient and the diabetes team to weigh the individual benefit.

rtCGM systems can be used either as stand-alone devices, e. $g$. for patients with ICT, or in combination with an insulin pump.

In sensor-augmented pump therapy ( $\mathrm{SaP}$ ), the rtCGM system is directly coupled to the pump. Whereas in the first generations the pump display was only used to display the rtCGM data, in current generations, the interaction has been further developed so that the insulin pumps stop the basal insulin infusion automatically if hypoglycaemia is imminent. In the future, rtCGM will enable the establishment of a closed loop (technical healing of diabetes). This means that the current glucose information is used to automatically adapt the infusion rate of an insulin pump to the glucose trend (Automated Insulin Dosing (AID)). For example, the two AID systems currently on the market outside Germany (and since September 2019 one in Germany as well) automatically adjust the basal rate but there is no fully automatic adjustment of insulin delivery for meals.
Almost all rtCGM systems also allow the measured values to be transferred to a cloud. From there, the data can be forwarded to family members or the diabetes team if the patient so desires (connectivity).

In addition, a long-term rtCGM system is available in which the sensor is inserted under the skin with minimal surgical intervention. The glucose concentration in the interstitial fluid is continuously calculated and transmitted to a smartphone/smartwatch by means of a transmitter which can be removed at any time from the skin above the transmitter. This is the only rtCGM system where vibration alarms of the transmitter are available directly on the body in addition to the usual alarms triggered by the smartphone/receiver. The sensor is removed by a certified physician after its functional period of up to 180 days.

In our opinion, the majority of patients who request a more intensive diabetes therapy should first use an rtCGM/iscCGM system together with an insulin pump. Studies demonstrate the benefit of rtCGM in patients who perform ICT with multiple daily injections in terms of HbA1c value improvement and reduction of hypoglycaemia risk. A rtCGM/iscCGM system is not a prerequisite for the optimal use of a CSII, but it is much simpler, more differentiated and safer to implement. One exception are children with type $1 \mathrm{di}-$ abetes, who should begin with an insulin pump and an rtCGM at the time of manifestation, especially at an age below $6-8$ years.

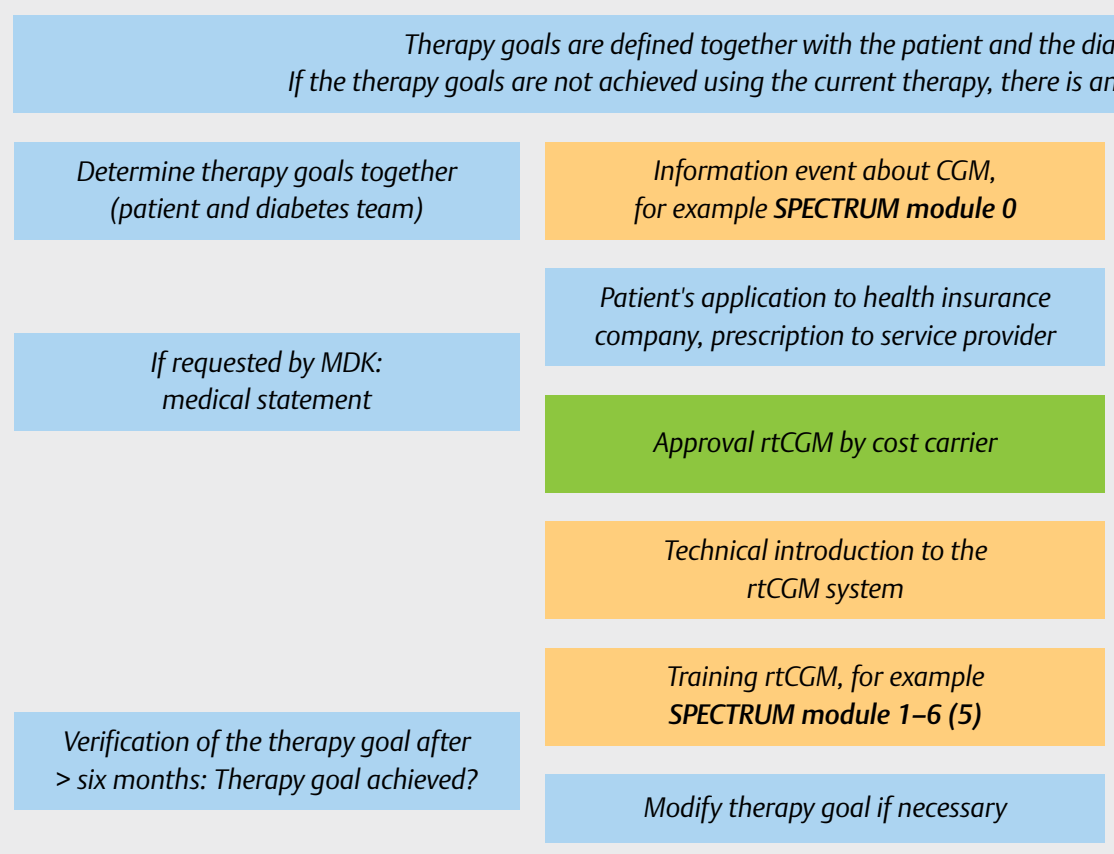

Test phase with self-motivation check, e.g. trial wearing on self-paying basis

\footnotetext{
The 1st generation iscCGM is on a self-paying basis or by individual contracts with the cost carriers. The 2nd generation iscCGM system has an catalogue number and is therefore prescriptible; it is treated the same as rtCGM systems.
}

Fig. 3 Practical procedure for starting rtCGM (blue: doctor/patient; yellow: training/introduction to technology; brown: costs approved or to be carried by the patient). 


\section{Measurement method}

In the transcutaneous needle sensors of the rtCGM systems currently available on the German market, glucose is measured using an enzymatic method (GOD, see SMBG) in the ISF in subcutaneous fatty tissue ( Table 5). The transcutaneous rtCGM systems have a life cycle of up to 10 days after which the glucose sensor should then be replaced according to the manufacturer's instructions. The sensors normally transmit an average value obtained every 5 min to the corresponding receiving device. As with blood glucose monitoring systems, medication can result in interferences (e.g. paracetamol, see device operating instructions) and all factors that have an influence on the measurement result must be taken into account ( Table 6).

With the implantable long-term rCGM systems, the glucose measurement is fluorescence-based which can lead to short-term measurement interruptions, especially at the beginning during bright sunlight.

\section{Available systems}

The rtCGM systems available to date were not directly intended to be used for a therapy decision (insulin dose adjustment); an adjustment of the insulin dose should therefore be based on the measurement result of an SMBG measurement and not on the CGM data (adjunctive usage). In practice, however, many patients rely on the accuracy of the rtCGM data and use them to make treatment decisions. There are now two rtCGM systems by one manufacturer where the therapy decision/insulin dose adjustment is permitted on the basis of the CGM measurement result (non-adjunctive usage), and other systems will follow. With the latest generation of one rtCGM system, there is no need for calibration (as with both iscCGM systems (see below)). However, calibration is possible, i. e. the measurement supplied by this rtCGM system can be related to the blood glucose value. In some patients, the accuracy of the measurement seems to be improved by one calibration per day, especially if this is done in the first days after the sensor is inserted. It should be noted that various factors influence the quality of rtCGM measurements (as well as for iscCGM systems). Such patient factors include the patient's BMI, the specific body site where the glucose sensor is inserted, the ambient temperature and the external pressure on the sensor (e. g. during sleep).

The performance of rtCGM systems is usually evaluated in clinical trials funded by the manufacturers. Head-to-head studies, in which patients wear more than one rtCGM system at the same time (up to 3 different systems, each with 2 devices from the same company), provide important information on the analytical performance of the rtCGM systems in direct comparison.

\section{Specifications for measurement quality/standards}

For the approval of rtCGM systems, there are no established standards for evaluating measurement accuracy as there are for SMBG monitoring systems. If and when this could take place cannot be foreseen. Recently, the U.S. Food and Drug Administration (FDA) published guidelines on how it believes the measurement quality of rtCGM systems should be characterized (iCGM). So far, only one system meets these requirements.

By defining the "Mean Absolute Relative Difference" (MARD), an attempt is made to describe the measurement quality of an rtCGM system. To determine the MARD value, the difference be- tween individual measured blood glucose values and simultaneously-determined rtCGM values is calculated. This value determined in clinical studies is significantly influenced by the study protocol used and the selection of the patients examined. The MARD value should therefore only be used as a guide.

Another parameter which deals with the measurement quality of an rtCGM system is the "Precision Absolute Relative Deviation" (PARD), calculated simultaneously for the same patient from the direct comparison (see above) of an rtCGM system with a second sensor from the same system.

\section{Costs/Refund of expenses}

Based on a positive assessment of benefit by IQWiG, the G-BA published a decision in 2016 providing for cost coverage of rtCGM if the patient submitting the application fulfils defined criteria (as is the case for therapeutic devices). The prescription for an rtCGM system can only be made by a specialist doctor such as: doctor of internal medicine, endocrinology and diabetology or a doctor of internal medicine specialised in general medicine/paediatrics/juvenile medicine with the recognition "Diabetologe DDG" (German Diabetes Society Diabetologist) or with comparable qualifications recognised by the respective regional medical association or doctors specialised in paediatrics and juvenile medicine with the paediatric endocrinology and diabetology recognition. In reality, the implementation of the G-BA decision varies greatly in the various KVs, despite the now available standardized guideline of the Health Insurance Medical Service/ Medizinische Dienst der Krankenversicherung (MDK).

The written application should be based on the MDK guideline and it might be helpful to use the rtCGM application proposal of the DDG/ AGDT (available online on the DDG and AGDT homepages). In addition to this application form, the MDK requests glucose protocols and accepts both digital and handwritten formats. The content of the protocols also varies between the different MDKs. It makes sense for patients to draw up a letter describing their individual prerequisites, daily requirements and motivation for using an rtCGM system.

In practice, the problem is that when a new CGM system comes onto the market, some manufacturers offer a type of 'exchange programme', while others do not. This can involve a justified change, e. g. to a new generation of sensor-supported pumps or to CGM systems with new functions. If company $X$ comes onto the market with a new pump linked to a CGM system and the patient still has a similar CGM system and performs ICT, experience shows that the change is difficult because the MDK initially wants the patient to try out pump X alone with the "old" CGM system. If the HbA1c value then decreases, the claim to a CGM system for the pump is voided; consequently, the patients actively prevent thisotherwise it would become necessary to write another letter of assessment explaining this paradox.

The time required by the diabetes team for the application, the medical instruction on the rtCGM systems and the training is not reflected by the cost carriers (health insurance companies). The EBM number in use since April 2017 is to be understood as a medical instruction number. Individual or group training courses are regulated differently throughout Germany depending on the federal state, KV district and cost carrier. Some health insurance companies do offer additional support. The AOK Baden-Württemberg, 


\begin{tabular}{|c|c|c|c|c|c|c|c|c|c|}
\hline 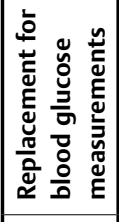 & 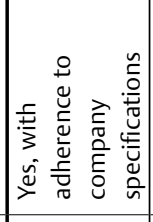 & 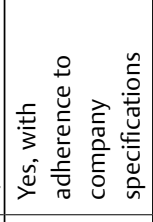 & 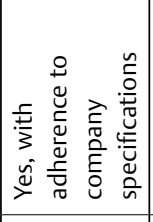 & 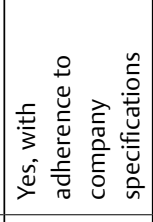 & 운 & 2 & z & 2 & 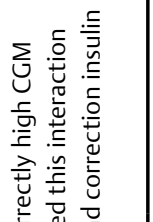 \\
\hline 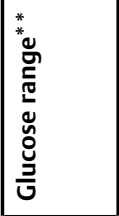 & 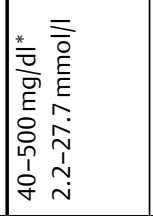 & 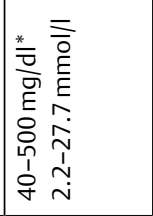 & 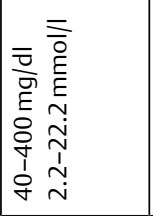 & 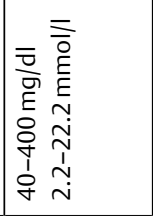 & 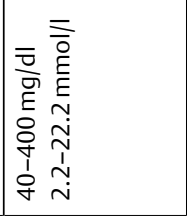 & & 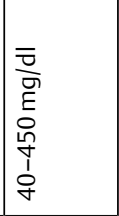 & 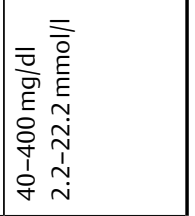 & 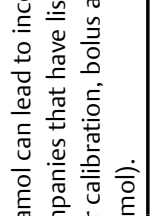 \\
\hline 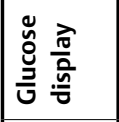 & 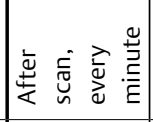 & 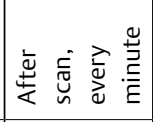 & 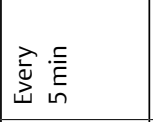 & 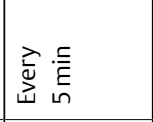 & 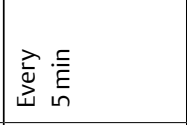 & & 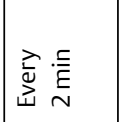 & \begin{tabular}{|l} 
离 \\
离
\end{tabular} & 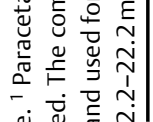 \\
\hline 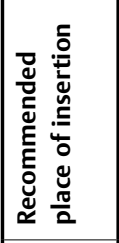 & 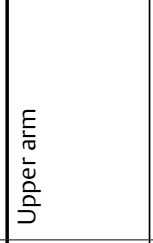 & 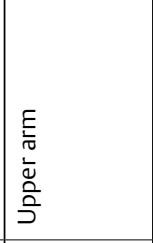 & 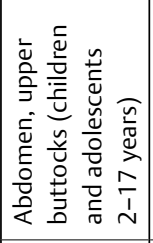 & 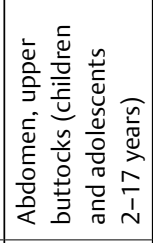 & 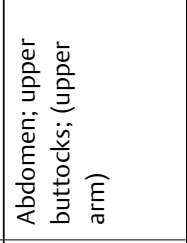 & & 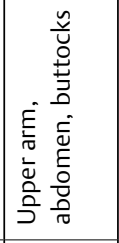 & 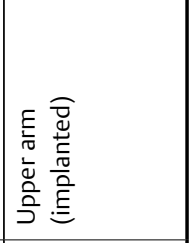 & 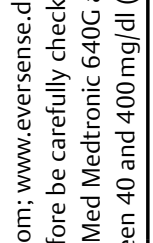 \\
\hline 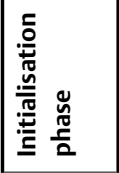 & $\stackrel{5}{-}$ & $\stackrel{5}{ᄃ}$ & $\stackrel{\Gamma}{\mathrm{N}}$ & $\stackrel{r}{\sim}$ & $\frac{\Gamma}{N}$ & & $\frac{\Gamma}{N}$ & $\frac{r}{d}$ & 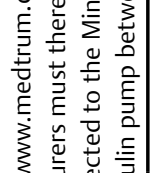 \\
\hline 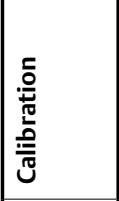 & 焉 & 焉 & $\stackrel{\check{\nu}}{\rightleftharpoons}$ & 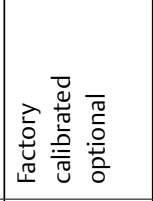 & 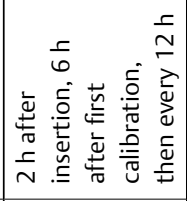 & & 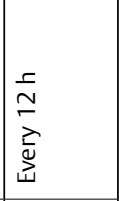 & 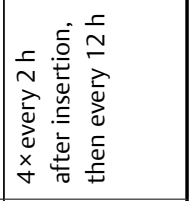 & 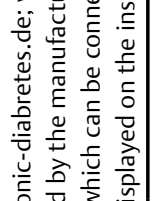 \\
\hline 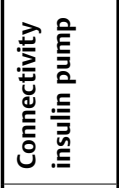 & z & z & $\stackrel{0}{z}$ & iz & z & 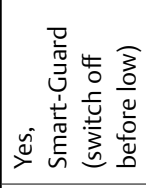 & 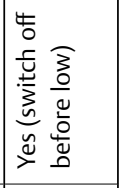 & z & 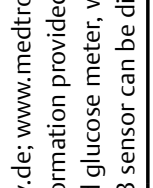 \\
\hline 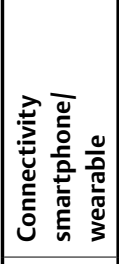 & 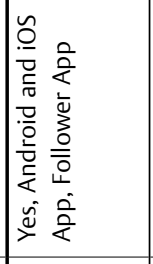 & 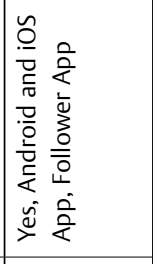 & 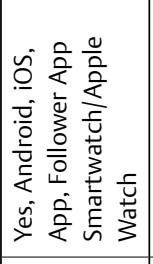 & 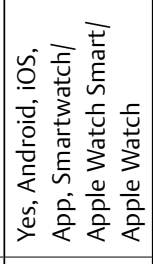 & 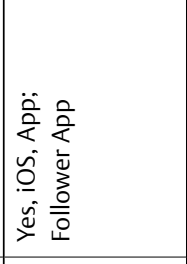 & z & 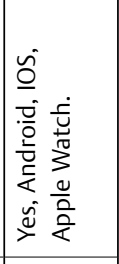 & 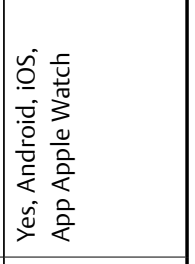 & 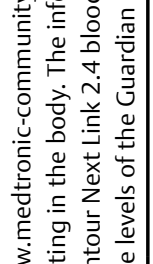 \\
\hline 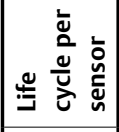 & 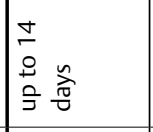 & 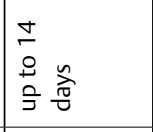 & 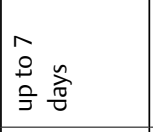 & 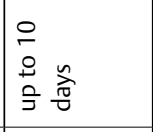 & 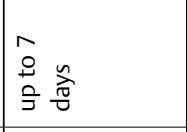 & \begin{tabular}{ll}
1 & \\
0 & $n$ \\
3 & \multirow{1}{0}{}
\end{tabular} & 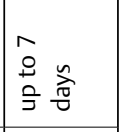 & 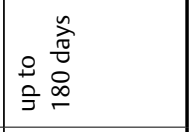 & 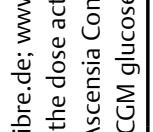 \\
\hline 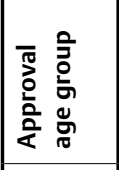 & 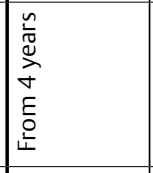 & 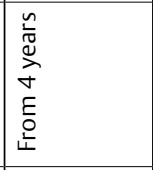 & 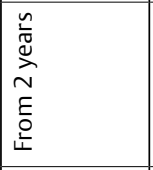 & 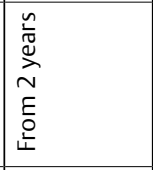 & 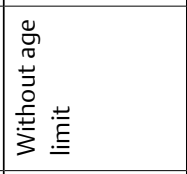 & 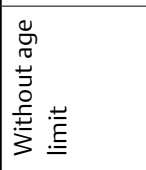 & 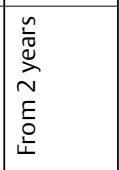 & 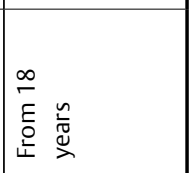 & 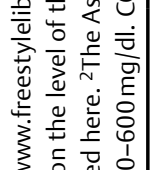 \\
\hline 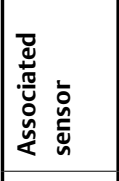 & 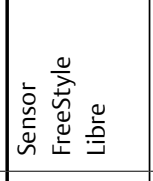 & 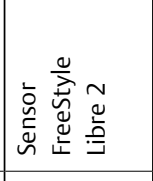 & 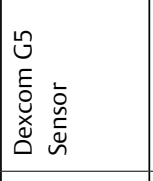 & 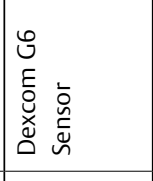 & 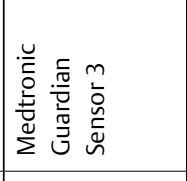 & 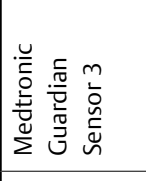 & 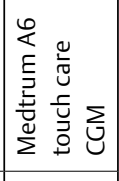 & 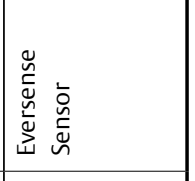 & 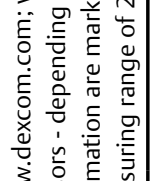 \\
\hline 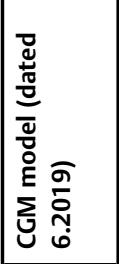 & 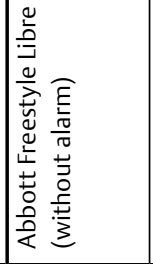 & 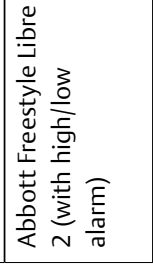 & 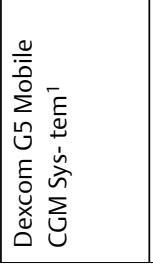 & 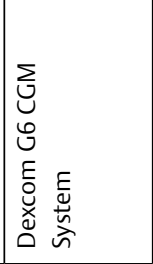 & 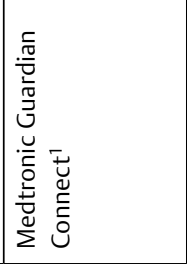 & 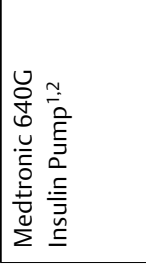 & 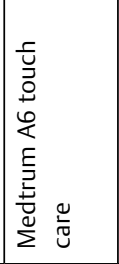 & 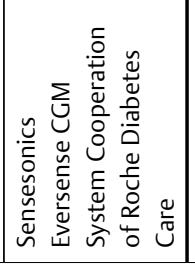 & 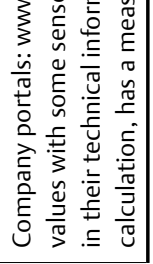 \\
\hline
\end{tabular}


- Table 6 Tips for interpreting the indications on the display of the CGM device. In the interpretation, the last 2-3 h of the trend curve must be taken into account. The meaning of the trend arrows varies from manufacturer to manufacturer.

\begin{tabular}{|c|c|c|c|c|c|}
\hline & Abbott Libre $1 / 2$ & Dexcom G5/6 & Medtronic Link 3 & Medtrum A6 & $\begin{array}{l}\text { Roche/Sensonics } \\
\text { Eversense }\end{array}$ \\
\hline$\rightarrow$ & $\begin{array}{l}<1 \mathrm{mg} / \mathrm{dl} / \mathrm{min} \\
<0.06 \mathrm{mmol} / \mathrm{min}\end{array}$ & $\begin{array}{l}<1 \mathrm{mg} / \mathrm{dl} / \mathrm{min} \\
<0.06 \mathrm{mmol} / \mathrm{min}\end{array}$ & & present & $\begin{array}{l}<1 \mathrm{mg} / \mathrm{dl} / \mathrm{min} \\
<0.06 \mathrm{mmol} / \mathrm{min}\end{array}$ \\
\hline$\searrow$ & $\begin{array}{l}1-2 \mathrm{mg} / \mathrm{dl} / \mathrm{min} \\
0.06-0.11 \mathrm{mmol} / \mathrm{min}\end{array}$ & $\begin{array}{l}1-2 \mathrm{mg} / \mathrm{dl} / \mathrm{min} \\
0.06-0.11 \mathrm{mmol} / \mathrm{min}\end{array}$ & & present & $\begin{array}{l}1-2 \mathrm{mg} / \mathrm{dl} / \mathrm{min} \\
0.06-0.11 \mathrm{mmol} / \mathrm{min}\end{array}$ \\
\hline$\uparrow \downarrow$ & $\begin{array}{l}>2 \mathrm{mg} / \mathrm{dl} / \mathrm{min} \\
>0.11 \mathrm{mmol} / \mathrm{min}\end{array}$ & $\begin{array}{l}>2 \mathrm{mg} / \mathrm{dl} / \mathrm{min} \\
>0.11 \mathrm{mmol} / \mathrm{min}\end{array}$ & $\begin{array}{l}1-2 \mathrm{mg} / \mathrm{dl} / \mathrm{min} \\
0.06-0.11 \mathrm{mmol} / \mathrm{min}\end{array}$ & present & $\begin{array}{l}>2 \mathrm{mg} / \mathrm{dl} / \mathrm{min} \\
>0.11 \mathrm{mmol} / \mathrm{min}\end{array}$ \\
\hline$\uparrow \uparrow \downarrow \downarrow$ & & $\begin{array}{l}>3 \mathrm{mg} / \mathrm{dl} / \mathrm{min} \\
>0.2 \mathrm{mmol} / \mathrm{min}\end{array}$ & $\begin{array}{l}>2 \mathrm{mg} / \mathrm{dl} / \mathrm{min} \\
>0.11 \mathrm{mmol} / \mathrm{min}\end{array}$ & present & \\
\hline$\uparrow \uparrow \uparrow \downarrow \downarrow \downarrow$ & & & $\begin{array}{l}>3 \mathrm{mg} / \mathrm{dl} / \mathrm{min} \\
>0.2 \mathrm{mmol} / \mathrm{min}\end{array}$ & & \\
\hline
\end{tabular}

for example, rewards the training for rtCGM (SPECTRUM) and for iscCGM (flash) under certain conditions.

\section{Quality control (Internal and external/ Interlaboratory tests)}

There are no quality controls for rtCGM systems. The SMBG measurements performed regularly for calibrating the rtCGM systems and further SMBG measurements are the only possibility for drawing conclusions about measurement quality. Carefully performing blood glucose measurements for calibration at times of low glucose fluctuations and correctly entering these values are prerequisites for obtaining reliable glucose measurements from rtCGM systems.

\section{Safety issues/Side effects}

There are a number of safety aspects to be considered when using this diagnostic option:

- What happens when the rtCGM measurement results are used to make therapy decisions?

- What is the quality used to detect low glucose levels, i. e. how well is hypoglycaemia detected in everyday life?

- What are the clinical consequences of miscalculations due to incorrectly performing SMBG?

- What incorrect measurements (= low glucose values) occur, e. g. when the patient lies on the sensor at night?

- Does the patient hear the alarms? Do they take place in time to be able to react adequately?

- As described in the rtCGM system operating instructions, SMBG measurements must be carried out when implausible results are obtained!

Only two rtCGM systems by one manufacturer are approved in Germany to date if patients want to adapt their insulin therapy based on the measurement results obtained by an rtCGM system; however, due to the predominantly good sensor measurement quality, this is also practiced by many patients using other systems. The measurement quality of rtCGM systems in the hypoglycaemic range is not satisfactory, therefore SMBG should be performed for symptoms indicative of hypoglycaemia (with conflicting rtCGM glucose values). SMBG measurement is also recommended if the rtCGM system indicates hypoglycaemia without symptoms of hypoglycaemia. In the case of rapid tissue glucose changes (induced e. g. by food intake or sport), there may be physiological and technical differences between the glucose concentrations in blood and ISF. These differences are not measurement errors, they stem from the fact that glucose is measured in two different compartments. The clinical experience of some diabetologists indicates that with such extreme differences, the alignment of therapy adjustments to rtCGM readings is safer than the alignment to SMBG readings alone.

rtCGM systems displays the glucose trend from the near past into the close future using trend arrows ( $\triangleright$ Table 6 ). It should be noted that the direction of the trend arrows can change rapidly, especially postprandially. For many people with diabetes, the trend arrows are an important basis for metabolic corrections, which is why their correct interpretation is a prerequisite for making correct therapy decisions.

So far, there have been no structured recommendations for widespread use. In a new publication by German experts on the interpretation of trend arrows, a first structured handling instruction was given. Although the proposals should be as generally-valid, manufacturer-independent, easily-understandable, concrete and practicable as possible, they nevertheless need to be individuallyadaptable in order to make therapy changes by using the interpretation of the trend arrow to adjust doses.

The use of trend arrows has quickly become better and more uniform thanks to tabular score cards in the form of rotating disks for adjusting the preprandial and/or postprandial insulin dose, the individual insulin sensitivity and the current starting glucose level. The score cards are available for different diabetes types and age groups. The aim is both to reduce short-term fluctuations in glucose levels and to favourably influence metabolism in the longterm. There is still a major need for properly-trained diabetes facilities to provide patients with differentiated, appropriate training so that they can make better use of the potential that trend arrows offer ( $\triangleright$ Table 5 ). In addition, care must also be taken to ensure that, in case of hypoglycaemia, the intervals between the intake of fast-acting carbohydrates are not too short ( $\vee$ Table 6 ), so that the intake of these substances does not result in hyperglycaemia.

Wearing glucose sensors on the skin with a plaster for several days and repeated use of the same skin site can lead to skin reactions in these areas. The reactions range from mild skin irritations to the development of contact allergies against components (especially acrylates) in the adhesives and/or the housing of the trans- 
mitters, which represent a considerable impairment and can make further use of a CGM system impossible. For these patients the implanted long-term rtCGM with daily changeable silicone plaster is a therapy option.

\section{Conditions to be observed in practice}

In all rtCGM systems, algorithms are integrated which convert the measured current flow or the fluorescence signals of the sensor into glucose values based on blood glucose calibration values, reduce the noise of the electronic measurement signal and eliminate implausible values. The algorithms of the companies are different (e. g. different time delays to blood glucose, different calibration methods, differences depending on the blood glucose meter used for calibration); little is known about how they work. This point should be considered by the patient when changing the rtCGM system. The handling and concept of the systems can also differ considerably. For this reason, the patient should receive proper instruction after a system change in order to understand the changes in the calibration process, the data evaluation with the new software and to react correctly.

\section{Use with different patient groups}

The G-BA decision sets out clear guidelines on the patient groups eligible for cost reimbursement of rtCGM systems, namely for insulin-dependent diabetes with ICT or CSII. In view of the number of people with type 2 diabetes (the scope of the costs) and the heterogeneity of this patient group, the decision on whether it makes sense for individual patients to use rtCGM can be quite varied.

The use of rtCGM makes sense in the following cases:

- In patients who perform ICT with multiple injections daily or with an insulin pump

- For patients with specific, individual problems (type 1 or type 2 )

- Temporarily for therapy review in patients taking oral antidiabetics that may induce hypoglycaemia

- During pregnancy

- In patients with pronounced secondary diseases, e. g. a painful peripheral polyneuropathy

- For training purposes

- To compensate for a handicap caused by diabetes at work

The only implanted long-term rtCGM system to date offers additional vibration alarms on the body and a plaster which is well-tolerated in patient and occupational groups with specific indications as compared to the transcutaneous rtCGM systems.

\section{Training/Psychological aspects}

rtCGM is a very potent, but also cost-intensive diagnostic and therapeutic tool. A prerequisite for optimal use, especially with regard to the modification of therapy, is that patients and medical staff are comprehensively trained. It is not considered sufficient for patients to be solely instructed by the manufacturers in device-specific aspects. The AGDT and AGPD have developed the manufacturer-independent rtCGM training program SPECTRUM. The time required to train patients in the diabetes practices is considerable and the patients themselves must receive qualified training. The training units can be taught individually or together, depending on the patient's needs; they can be taught to groups or individuals in both outpatient and inpatient settings. In the case of children, the MDK in individual $\mathrm{KV}$ s rejects the 3-day inpatient training courses (SPECTRUM modules 1-4), although this is the only option for many clinics ( = no day clinic, outpatient generally not billable). Furthermore, some families need more time (migration background, language problems, social hardships, calculation problems) when dealing with readjustment of the system and simultaneous training and also need individual instruction throughout the day. The G-BA decision on the necessity of a training course on rtCGM does not specify how and in which setting it is to take place.

An evaluation study for SPECTRUM ( = CGM TRAIN) has been started; this is the prerequisite for this training to be billable. Only when this is possible can diabetologists widely offer such time-consuming and personnel-intensive training courses.

Patients with a CGM system should not only receive initial training but should also be trained over time in order to make optimum use of the possibilities of rtCGM-supported therapy and because of the new generations of devices that are constantly being developed.

For patients, the permanent availability of information on the glucose trend in their own bodies can be both a blessing and a curse. On the positive side, rtCGM warns of acute events and helps optimise glucose control. Patients who make intensive use of the information and advice provided by the rtCGM systems report a significant increase in safety, freedom and quality of life; this applies in particular to children and their families. Many parents can sleep through the night for the first time in years without having to get up several times at night to carry out an SMBG. Furthermore, the reduction in lancing for SMBG measurements, especially in children, is a significant psychological relief.

On the other hand, the rtCGM system constantly reminds the patient of diabetes. Frequent alarms (e. g. when alarm limits have not been sensibly programmed) can disturb and unsettle patients and their relatives immensely, especially if they are false positives. Some patients feel bothered by constantly wearing a technical system in everyday life and their body awareness is impaired. As a result, these patients do not wear the rtCGM system continuously, but only situatively. Other patients are not in agreement with their readings being passed on to family members or members of the diabetes team. They see it as an invasion of their privacy with negative feedback and consequences.

Proper training and experience with rtCGM systems is important not only for patients, but also for diabetes teams. The requirement should be that physicians who care for patients with CGM systems have sufficient experience with the different systems and data analyses. In addition, the required software should also be available in the doctor's office and used during consultation with the patient.

Even if the insertion and removal of the implantable long-term rtCGM system can be performed by diabetologists who are usually not surgically active, and it can be integrated into the standard procedure, sufficient experience and ongoing routine are still necessary. The physician carrying out the procedure must be certified accordingly by the manufacturer. It is also advisable that only practices or clinics that continuously perform these procedures in sufficient numbers function as centres. 


\section{Comment}

Continuous glucose monitoring is rapidly gaining importance in the context of modern diabetes therapy due to the advantages of the permanent availability of glucose data and the reduction (to prevention) of hypoglycaemia and glucose fluctuations.

One requirement of the G-BA decision is that data security must be safeguarded when using an rtCGM system, i. e. the measured data (even if uploaded to a cloud) should not be accessible and traceable for third parties. It is therefore important to inform patients of the legal situation in this respect.

Each manufacturer offers its own software for evaluating rtCGM data. The software programs can be complex in parts and require an introduction. In order for CGM data to be read and analysed more frequently (whether by the users or the diabetes team), it would be extremely helpful to standardise the evaluation and presentation of the data. There are concrete proposals for the presentation of the measured values in a recent consensus paper on CGM. The Ambulatory Glucose Profile (AGP) is only of the options recom- mended for the analysis of the data ( $\vee$ Fig. 4). For data analysis with AGP there are practical recommendations. A workbook with case studies is used for the consecutive therapeutic conclusions.

Manufacturers periodically bring new generations of their rtCGM systems onto the market - with improvements in measurement quality, more simplified handling, improvements in interoperability and connectivity. If such models (or a combination of insulin pump and rtCGM) offer the patient a relevant therapeutic advantage, it should be possible to apply for a change before the expiry of the one-year flat-rate care charge (rtCGM) or four-year flat-rate care charge (insulin pump). There are a number of innovative measurement principles in preclinical and clinical development that will address some of the drawbacks of the rtCGM systems available to date, as well as offer new options and be more cost-effective to manufacture.

The constant availability of glucose values in rtCGM systems makes it possible to supply bolus computers with significantly more data than was previously possible with SMBG values; however, there

\begin{tabular}{|c|c|c|}
\hline Ambulatory glucose profile & Assessment & Possible sources \\
\hline & \multicolumn{2}{|l|}{$\begin{array}{l}\text { - Low variability in IDR and IQR } \\
\text { - Low glucose variability } \\
\text { - Comparable with glucose variability } \\
\text { of a person with a health metabolism }\end{array}$} \\
\hline & $\begin{array}{l}\text { - Low variability in IDR } \\
\text { - High variability in IQR } \\
\text { - Modification of therapy required }\end{array}$ & $\begin{array}{l}\text { Resulting from the therapy*: } \\
\text { - Insulin dose } \\
\text { - Incorrect carb unit/bread unit factor } \\
\text { - Incorrect correction factor } \\
\text { - Constantly changing times/day patterns }\end{array}$ \\
\hline IDR & $\begin{array}{l}\text { - Low variability in IQR } \\
\text { - High variability in IDR } \\
\text { - Modification required }\end{array}$ & $\begin{array}{l}\text { Resulting from behaviour*: } \\
\text { - Meals not covered } \\
\text { - Unsuitable interval between injecting } \\
\text { and eating } \\
\text { - Irregular mealtimes: occasional, varying } \\
\text { times/day patterns } \\
\text { - Exercise } \\
\text { - Alcohol } \\
\text { - Incorrect carb unit/bread unit factor }\end{array}$ \\
\hline IQR & $\begin{array}{l}\text { - High variability in IDR and IQR } \\
\text { - Modification of therapy required }\end{array}$ & $\begin{array}{l}\text { Resulting from therapy and behaviour*: } \\
\text { - Insulin dose } \\
\text { - Incorrect carb unit/bread unit factor } \\
\text { - Incorrect correction factor } \\
\text { - Meals not covered } \\
\text { - Unsuitable interval between injecting } \\
\quad \text { and eating } \\
\text { - Irregular mealtimes } \\
\text { - Exercise } \\
\text { - Alcohol }\end{array}$ \\
\hline $\begin{array}{l}\text { Ig. } 4 \text { Examples of interquartile } \\
\text { estricted by an irregular daily ro } \\
\text { ge, } 10^{\text {th }}-90^{\text {th }} \text { percentiles). }\end{array}$ & $\begin{array}{l}\text { erdecile glucose variability and possible cat } \\
\text { R: interquartile range (interquartile range, }\end{array}$ & $\begin{array}{l}\text { glucose fluctuations. }{ }^{*} \text { The assessment of the } \\
\text { rcentiles), IDR: interdecile range (interdecile }\end{array}$ \\
\hline
\end{tabular}


are still no corresponding systems. Alternatively, the rtCGM values can be transferred to apps on smartphones in the future and their algorithms can make suggestions for the insulin dose.

\section{Intermittent Scanning CGM (iscCGM)}

\section{Targets/Indications}

The use of iscCGM uses trend displays of the currently scanned glucose value and the presentation of retrospective CGM data to help achieve therapy goals by avoiding acute complications. The measurement technology of the iscCGM systems (see below) is based on a technology similar to that of rtCGM systems. The costs of this option are lower than those of rtCGM systems. However, the first version of the iscCGM system did not have an alarm function ( $\vee$ Table 5). Similar to SMBG, the success of the follow-up depended on the patient being active. Nonetheless, iscCGM already brought a reduction in the frequency of lancing the finger and a scanning process requiring minimal effort. With the second generation of devices, it has become possible to turn on threshold limit alarms (hypoglycaemia alarm, hyperglycaemia alarm). However, this method does not directly reflect the currently-measured value, the value this is only available after an active scan. The AGDT has prepared an updated statement on replacing blood glucose measurements by measurements using rtCGM or iscCGM systems (https://www. deutsche-diabetes-gesellschaft.de/fileadmin/ Redakteur/Stellung- nahmen/2019/Stellungnahme_der_ AGDT_2019_5_28_clean.pdf). Currently, the National Association of Statutory Health Insurance Funds (Spitzenverband der Gesetzlichen Krankenversicherung GKV) has decided that these secondgeneration devices are an rtCGM system as per the G-BA decision, and that they will be included in the catalogue of therapeutic devices and aids, and can therefore be prescribed. In terms of cost allocation, there is then no longer any differentiation between rtCGM and iscCGM. With the introduction of the Medical Devices and Therapeutic Devices Reform Act 2017/Hilfsmittel- und Heilmittelreformgesetzes 2017, it was stipulated the GKV must examine medical devices for which a listing is submitted within 3 to 6 months. The GKV examines whether there is a significant change to a method that has already been evaluated. If the GKV comes to the conclusion that this is not the case, the application is approved, and the aid is included in standard care.

However, there are differences between rtCGM systems and iscCGM systems because regular automatic transmission and display of the values to a receiver does not take place with iscCGM. An iscCGM cannot be calibrated either. Furthermore, it is possible to switch off the alarm functions and the selection of different alarm functions is limited to threshold alarms. In order to be able to provide the individual patient with the best option for a CGM system, we still consider a medical differentiation between rtCGM and iscCGM systems to be useful.

\section{Measurement method}

From a measurement point of view, iscCGM is a transcutaneous CGM method based on electrochemical needle sensor technology with low drift of the measurement signal. The manufacture of these sensors can be standardised in such a way that calibration of the glucose measurement during manufacture is possible and no further calibration by the patient is required. Therefore, patients can largely do without SMBG, unless, e. g., hypoglycaemia symptoms do not match the values and the glucose trend displayed, or very high glucose values or strong glucose fluctuations are present. Due to the factory calibration, calibration errors by the patient are not possible with iscCGM. However, the iscCGM measurement cannot be related to the current blood glucose value if there are discrepancies. As with all CGM systems, the prerequisite for measurement quality is consistently high sensor quality during production. This is a particular challenge for all sensor manufacturers as production increases.

\section{Available systems}

Two iscCGM systems by the same manufacturer are currently available on the market ( $\triangleright$ Table 5). The life cycle of the iscCGM sensor is 14 days. To transfer the data, the reader or a smartphone with the corresponding app must be actively brought by the user to the inserted glucose sensor. The continuously monitored glucose values (every $15 \mathrm{~min}$ ) of the last $8 \mathrm{~h}$ and the current value are transmitted and displayed on the device the current glucose value, a trend arrow and a glucose profile. If the device has measured low or high glucose values since the last scan, the first generation of devices provides this information when transferring the values to the reader. A direct alarm function appeared in the next model which emits an alarm message if the glucose value exceeds or falls below a set threshold. However, an active scan must first be performed to display the current glucose value and the type of alarm. Irrespective of the new alarm function, data must still be retrieved every $8 \mathrm{~h}$ by scan so that no data gaps occur. There is no automatic transmission and recording of all measured values to/from the receiver.

Many patients now use an app on their smartphone to read or scan the data. It is important to consider which glucose sensors can be read with which device generation of the readout device.

\section{Specifications for measurement quality/standards}

Just as for rtCGM systems, there are no established standards for assessing the measurement quality of iscCGM systems. Studies have provided information on the MARD value of this system.

\section{Costs/Refund of expenses}

The second generation iscCGM system has a general alarm function that is differentiated by scanning into hypoglycaemia/hyperglycaemia alarm or contact loss. At present, IQWiG has not performed an assessment of benefit for iscCGM (in the older version without alarm and the new version with alarm). Despite this initial legal situation, the iscCGM system has now been included in the index of health insurance aid numbers, based on the considerable interest in this iscCGM system by a large number of people with diabetes and as a more cost-effective alternative to rtCGM systems. Some health insurance companies no longer reimburse the cost of test strips for SMBG if an iscCGM has been approved; others try to replace the iscCGM system with approved rtCGM systems.

\section{Quality control by the user (Internal and external/ Interlaboratory tests)}

There are no quality controls for the iscCGM systems. The SMBG measurements for calibration, which need to be carried out regu- 
larly, are no longer necessary, so that no conclusions can be drawn about the measurement quality of these systems in everyday life. However, the manufacturer expressly describes the necessity of additional SMBG measurements in certain situations in the respective operating instructions.

\section{Safety issues/Side effects}

As with rtCGM, there are security aspects to be considered when using iscCGM (see above). Since there are no regular calibration measurements, it is not possible to monitor whether the iscCGM system exhibits sufficient measurement quality in specific individual cases and situations. In this system too, patients should perform SMBG measurements according to the specifications in the operating instructions (e. g. in the case of hypoglycaemia symptoms, especially in low but also in very high glucose ranges), regardless of what the iscCGM system indicates.

Wearing glucose sensors on the skin for 14 days and repeated use of the same skin site can lead to skin reactions in these areas. The reactions range from mild skin irritations to the development of contact allergies in some patients. The allergic reaction is not only a considerable impairment, it can make the further use of this system impossible and can lead to accompanying reactions to the plasters when using other technical systems (e. g. an insulin pump).

\section{Conditions to be observed in practice}

The iscCGM system data can be read and analysed with a company-specific software. In everyday life it should be noted that sensor artefacts (these are long hypoglycaemic episodes displayed which have not actually occurred) can occur as a result of lying on the sensor while sleeping; this also applies to rtCGM systems with needle sensors.

\section{Use with different patient groups}

iscCGM can be used in patients who perform ICT or CSII without pronounced hypoglycaemia perception disorder. The use of iscCGM should also be considered in cases of less complex therapy schemes ( $\triangleright$ Fig. 1). Thus, the use of iscCGM can also be intermittent, i. e. adapted to requirements, in oral therapy with hypoglycaemia risk, during therapy changes or while participating in a training course. The results of a clinical study are available for patients with type 1 and type 2 diabetes who are undergoing intensified insulin therapy.

\section{Training/Psychological aspects}

There is a training program (flash) for iscCGM, which was evaluated in a clinical study. The development was financed by the manufacturer of the system and is tailored to this product. Some differences, especially the lack of alarms in the first generation iscCGM system, result in the training course covering different topics than the rtCGM training program. Some patients find it beneficial not to be constantly disturbed by alarms, especially during the night. The self-determined, occasional retrieval of glucose values and the omission of calibration measurements are also deemed pleasant.

The second generation of devices allows the activation of a high and a low alarm and, after an alarm message by a scan, displays the current measured value. The high and low alarms are distinguished by acoustically different alarm tones. These newly available options require additional training similar to rtCGM systems.

\section{Comment}

There is no general reimbursement or EBM number for training and consultation on iscCGM systems. For the diabetes team, this means that the care effort in most KV areas is not rewarded.

\section{HbA1c}

\section{Goals/Indications}

The long-term quality of glucose control has a direct influence on the risk of the occurrence of diabetes-associated secondary diseases. The HbA1c value measurement allows an evaluation of the glucose control over time. The HbA1c value is mainly determined by the blood glucose values of the last 2-3 months and has been used in diabetology for many years as a quality indicator for glucose control. However, the HbA1c value does not permit an adequate statement on glucose variability. The attending physician should set an HbA1c therapy goal based on the individual situation of the patient. In particular, if a patient does not perform SMBG, an HbA1c measurement at quarterly intervals is necessary to obtain an overview of the quality of glucose control. If the patient performs type of self-testing, the HbA1c value must always be evaluated in combination with the results of the self-testing. As considerable intraand interindividual deviations between the measured $\mathrm{HbA} 1 \mathrm{c}$ value and the simultaneously-determined SMBG values can occur in individual patients, e.g. due to diseases or other factors, the HbA1c value should never be considered on its own ( $>$ Table 7).

In practice, the measurement of other glycated proteins (e. g. fructosamine) is of secondary importance.

\section{Measurement method}

There are a number of different methodological approaches to measuring $\mathrm{HbA} 1 \mathrm{c}$; in practice, a few have become established and are frequently used.

\section{Available systems}

There are various systems on the market; they can be differentiated according to measuring principles and laboratory systems, POCT (Point of Care) systems and small desktop devices that can also be used by patients.

\section{Specifications for measurement quality/standards}

In recent decades, the measurement quality of the $\mathrm{HbA} 1 \mathrm{c}$ value measurement has been significantly improved by a number of measures, in particular by the creation of suitable reference material. However, there are still considerable differences in measurement results between laboratories using identical blood samples; even intra-laboratory differences can be substantial.

\section{Costs/Refund of expenses}

The costs for the HbA1c value measurements are borne by the cost carriers for all patients with diabetes. 
- Table 7 Causes for incorrect HbA1c values.

\begin{tabular}{|c|c|c|c|}
\hline \multicolumn{4}{|c|}{ Physiological causes } \\
\hline & Falsely low & Falsely high & Opportunities \\
\hline \multirow[t]{7}{*}{ Erythrocyte formation } & Increased & $\begin{array}{l}\text { Slows down due to lack of available } \\
\text { iron }\end{array}$ & \multirow{13}{*}{$\begin{array}{l}\text { - Determination of a "HbF-adjusted" } \\
\text { - HbA1c } \\
\text { - Reticulocytes + Ferritin } \\
\text { - Urea } \\
\text { - Hb electrophoresis } \\
\text { - For Hb variants, determine HbA1c } \\
\quad \text { using an immunological method. } \\
\text { - Fructosamine }\end{array}$} \\
\hline & Very high & Iron deficiency anaemia & \\
\hline & Pregnancy & Infectious anaemia & \\
\hline & Bleeding, blood loss & Tumour-induced anaemia & \\
\hline & Blood transfusion & & \\
\hline & Erythropoietin administration & & \\
\hline & Iron supplementation & & \\
\hline \multirow[t]{6}{*}{ Erythrocyte breakdown: } & Too soon & Too late & \\
\hline & Haemolytic anaemia & Splenectomy & \\
\hline & Chronic renal insufficiency & Aplastic anaemia & \\
\hline & Cirrhosis of the liver & & \\
\hline & Folic acid deficiency? & & \\
\hline & $\begin{array}{l}\text { Hemoglobinopathies: } \\
\text { - HbS } \\
\text { - HbC } \\
\text { - HbD }\end{array}$ & $\begin{array}{l}\text { Hemoglobinopathies: } \\
\text { - HbH } \\
\text { - HbF (Thalassemia) }\end{array}$ & \\
\hline \multicolumn{4}{|c|}{ Spherocytosis } \\
\hline \multirow{5}{*}{$\begin{array}{l}\text { Laboratory technical } \\
\text { causes }\end{array}$} & & & \\
\hline & $\begin{array}{l}\text { False high - ONLY for HPLC- HbA1c } \\
\text { measurements through carbamyla- } \\
\text { tion }\end{array}$ & $\begin{array}{l}\text { False high - ONLY for immunologi- } \\
\text { cal HbA1c measurements }\end{array}$ & Possibilities for objectification: \\
\hline & $\begin{array}{l}\text { Terminal renal insufficiency, uraemia, } \\
\text { crea }>5 \mathrm{mg} / \mathrm{dl}\end{array}$ & Betalactam antibiotics & $\begin{array}{l}\text { - Newer HPLC columns are no longer } \\
\text { influenced by carbamylation, ask } \\
\text { laboratory. } \\
\text { - Laboratory method other than } \\
\text { HPLC required: } \\
\text { - Immunological technique } \\
\text { - Enzymatic technique } \\
\text { (written note on the laboratory } \\
\text { request form) }\end{array}$ \\
\hline & Alcoholism (acetaldehyde) & Contraceptive pill & \\
\hline & Aspirin (from $500 \mathrm{mg} / \mathrm{d}$ over weeks) & HAES & \\
\hline \multicolumn{4}{|l|}{ Other causes } \\
\hline & Falsely low & Falsely high & \\
\hline & Nutritional (alcohol, fat) & $\begin{array}{l}\text { Pharmaceuticals: } \\
\text { - Immunosuppressants } \\
\text { - Protease inhibitors }\end{array}$ & \\
\hline & & $\begin{array}{l}\text { Genetically-induced hyperglycation } \\
\text { in certain ethnic groups }\end{array}$ & \\
\hline & & Age & \\
\hline & & Organ transplantation & \\
\hline & & Hypertriglyceridemia & \\
\hline & Hereditary causes & Hereditary causes & \\
\hline
\end{tabular}

\section{Quality control (Internal and external/ Interlaboratory tests)}

According to the specifications of the Rili BÄK for HbA1c, the operators of corresponding devices must participate in an internal and external quality control. Unit-use POCT systems are excluded from external quality control; if $\mathrm{HbA} 1 \mathrm{c}$ is used for diabetes diagnosis, interlaboratory comparisons are required. Up until now, the guideline for the pass limit for external quality control ( = interlab- oratory comparisons) was $\pm 18 \%$. In future, this figure will be reduced to $8 \%$ (with a transition period of several years). The requirements for internal quality control will be simultaneously reduced from $10-3 \%$. Furthermore, commutable (exchangeable) control material (whole blood) is now used in the interlaboratory comparisons, which improves quality control considerably. Overall, this measure contributes to a significant improvement in the measurement quality of this parameter, which is important for diabetology. 


\section{Safety issues/Side effects}

When using different $\mathrm{HbA} 1 \mathrm{c}$ measuring methods, differences are observed that are relevant for therapy: Various systems can display HbA1c measured values differing by $0.5 \%$ for the same blood sample. If a patient has a relatively low therapeutic target, such differences may increase the risk of hypoglycaemia. The erythrocyte life span has a considerable influence on HbA1c. Diseases that change the erythrocyte life span, correspondingly influence the $\mathrm{HbA} 1 \mathrm{c}$ value ( Table 7). For example, due to the significantly shortened erythrocyte life span, pronounced haemolytic anaemia can lead to low $\mathrm{HbA1c}$ values which are independent of the mean glucose values.

\section{Practical implementation of the measurement}

Information on the practical implementation and interpretation of the measurement results is provided in the Diabetes Diagnosis practical recommendation. An HbA1c value (eHbA1c) can be calculated from fasting glucose values measured over a certain period of time and individual 7-point blood glucose profiles. Using rtCGM data, a glucose management index (GMI) can be calculated in addition to $\mathrm{HbA} 1 \mathrm{c}$ that reflects the predominant quality of glucose control from such data over a period of time. At the request of the American health authorities, another term is used to avoid suggesting that this parameter corresponds to the HbA1c value.

\section{Conditions to be observed in practice}

The use of POCT devices for HbA1c value measurement allows the currently measured $\mathrm{HbA} 1 \mathrm{c}$ value to be discussed directly with the patient. There is also no need to send a blood collection tube to a laboratory. However, the measurement quality of all POCT systems is not sufficient.

\section{Use with different patient groups}

The HbA1c value measurement provides the desired information on long-term glucose control in almost all diabetes types. In older patients it should be noted that the HbA1c value increases physiologically (see Diabetes Diagnosis practical recommendation).

\section{Training/Psychological aspects}

In diabetes training, the concept of the HbA1c value should be explained to the participants so that they understand the importance of target values and work towards achieving their target values. However, thanks to the availability of CGM data, the focus can be placed on the reduction of glucose fluctuations as a medium-term therapeutic goal. If individual patients are deeply afraid of severe hypoglycaemia, they will tend to aim for rather high $\mathrm{HbA1c}$ values. The opposite is true for patients whose goal it is to avoid diabetes-associated sequelae ("low-flying patients") because of extreme fear.

\section{Comment}

In principle, the use of rtCGM/iscCGM systems also provides an overview of the quality of glucose control over time. Thus, an average glucose value over time can be calculated that correlates with the $\mathrm{HbA} 1 \mathrm{c}$ value. The importance of the $\mathrm{HbA} 1 \mathrm{c}$ value remains high despite the availability of CGM data. The HbA1c value is currently the only relevant surrogate endpoint associated with subsequent complications. New endpoints that are obtained by properly eval- uating the data provided by CGM systems, such as "Time-in-Range" (TiR) and "Time-below-Range" (TbR), facilitate the assessment of glucose control quality ( Table 4). The TiR and TbR, for example, better reflect fluctuations in glucose concentrations than the HbA1c value, but the parameters in the software programmes of the various manufacturers are also system-dependent. In our view, parameters derived from CGM, such as TiR/TbR, complement but do not replace the $\mathrm{HbA} 1 \mathrm{c}$ value.

(https://www.deutsche-diabetes-gesellschaft.de/file- admin/ Redakteur/Stellungnahmen/2019/20190509_KLD_Stel- lungnahme_Time_in_Range_2019_final.pdf)

The measurement quality of the CGM system used has an influence on the TiR.

\section{Summary and Outlook}

The glucose measurement and control options presented have revolutionized diabetes therapy over the past 40 years, providing patients with an unprecedented degree of flexibility and safety in dealing with their disease.

This development has accelerated significantly over the last two decades, and the market launch of AID systems will represent another quantum leap in diabetes therapy.

All methods for glucose monitoring are subject to rapid change and further development. Therefore, the statements formulated here should be continuously updated through current literature reviews and observance of the manufacturers' homepages. There is a need for an independent institute to evaluate the performance of the measurement systems on the market, especially after their market launch. This is also due to the weaknesses of the previous CE marking system. It will take years before the improvements that come with the currently revised CE system take effect.

Unfortunately, there is no European authority which is primarily concerned with medical devices (as is the case with medicine); this is covered by the EU Commission. The German authorities (BfArM) also have relatively few practical options, since medical devices are a country issue. A dialogue between all parties involved, i. e. manufacturers, cost carriers, health policymakers, practitioners and patients - under the leadership of the German Diabetes Society/AGDT - in the format of a round table would help to identify and remedy deficiencies in order to significantly improve the situation.

\section{Acknowledgement}

Our heartfelt thanks go to the many colleagues who have helped us with constructive comments.

\section{German Diabetes Association: Clinical Practice Guidelines}

This is a translation of the DDG clinical practice guideline published in: Diabetologie 2019; 14 (Suppl 2): S119-S141 


\section{Conflict of Interest}

$\mathrm{LH}$ is active as a consultant in the development of new diagnostic options for various companies (e.g. Roche Diagnostics, Sanofi, Abbott). He is a shareholder and consultant in Profil - Institut für Stoffwech- selforschung, Neuss, and ProSciento, San Diego, USA.

DD received lecture fees from Abbott, Dexcom, Lilly, Menarini, Novo Nordisk, Roche Diagnostics, Senseonics and is a member of advisory boards of BD, Profusa, Roche and Senseonics. TS received lecture fees from Abbott, Ascensia, Astra Zeneca/Bristol- Myers Squibb, Bayer, Berlin-Chemie, Boehringer Ingelheim, Eli Lilly, Medtronic, MSD,

Novartis, Novo Nordisk, Sanofi. He is a member of advisory boards of Abbott, Ascensia, Bayer Vital, Boehringer Ingelheim, Eli Lilly, Janssen, Medtronic, MSD, Novo Nordisk, Sanofi and has received support for scientific projects from: Astra Zeneca/Bristol-Myers Squibb, Becton Dickinson, Eli Lilly, MSD, Novo Nordisk, Sanofi. SVS has worked as a consultant for Abbott, Dexcom, Lilly, Medtronic, NovoNordisk and Roche for the past 3 years. SVS has received lecture fees and travel expenses from the following companies in the last 3 years: Abbott,
Berlin-Chemie, BPI, Lilly, Merck-Serono, Medtronic, NovoNordisk and Pfizer. MN was a consultant and speaker for the following companies: Abbott, Berlin- Chemie, MSD, Sanofi, Medtronic, Bayer Diagnostics, Astra Zeneca. SvS is in an advisory function on the Advisory Board for the optimisation of aids, medicines and information materials for children with diabetes for several companies (Abbott, Eli Lilly, Medtronic, Novo Nordisk, Dexcom). In the last 2 years she has received lecture fees from Abbott, Berlin Chemie, Eli Lilly, Medtronic, Merck, Novo Nordisk, Roche and Sanofi. KL received lecture fees from Astra Zeneca, BDI, Lilly Deutschland, Medtronic, Menarini/Berlin-Chemie, Merck Serono, MSD SHARP \& DOHME, Novo Nordisk, Roche Diabetes Care, Sanofi-Aventis. She is a member of the Advisory Boards of Roche Diabetes Care, Medtronic, Dexcom and Sanofi-Aventis. GF is the medical director of IDT (Institut für Diabe tes-Technologie Forschungsund Entwicklungsgesellschaft mbH at the University of Ulm, Ulm), which carries out clinical studies on medical products for diabetes therapy on its own initiative or on behalf of various companies. GF/IDT has received lecture/consultation fees from Abbott, Ascensia, Dexcom, LifeScan, Menarini Diagnostics, Metronom Health, Novo Nordisk, Roche, Sanofi, Sensile and Ypsomed. 